Portland State University

PDXScholar

6-1-1967

\title{
A scale of verbal accessibility in marriage
}

\author{
Barbara F. Kresse \\ Portland State University \\ Judith M. DeCourcy \\ Dolores M. McLennan \\ Naomi S. Mansfield \\ David A. Wickwire
}

Follow this and additional works at: https://pdxscholar.library.pdx.edu/open_access_etds Let us know how access to this document benefits you.

\section{Recommended Citation}

Kresse, Barbara F.; DeCourcy, Judith M.; McLennan, Dolores M.; Mansfield, Naomi S.; and Wickwire, David A., "A scale of verbal accessibility in marriage" (1967). Dissertations and Theses. Paper 65. https://doi.org/10.15760/etd.65

This Thesis is brought to you for free and open access. It has been accepted for inclusion in Dissertations and Theses by an authorized administrator of PDXScholar. Please contact us if we can make this document more accessible: pdxscholar@pdx.edu. 


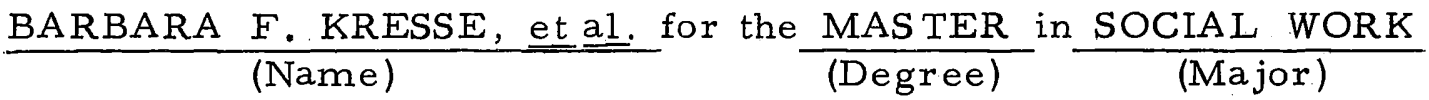

Date thesis is presented May 16,1967

Title: A SCALE OF VERBAL, ACCESSIBILITY IN MARRIAGE Abstract Approved

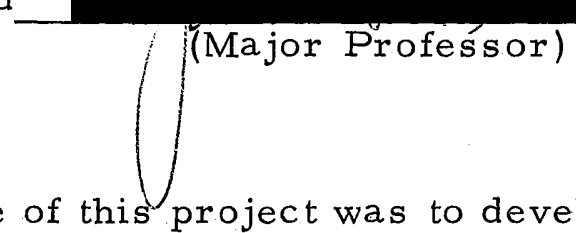

The purpose of this project was to develop a tool to clarify one concept of verbal interaction in marriage. This concept, Verbal Accessibility, was developed by Norman Polansky and defined as the degree of readiness of the individual to communicate verbally and to participate in communication about his determinant attitudes. Verbal Accessibility is dependent on two variables: 1) the enduring characteristics of the individual, and 2) the release of inhibiting factors in a given situation.

In order to facilitate the use of this concept in treatment, a scale was needed to measure Verbal Accessibility of both the person and of the attitudes in and about marriage. The present study began the development of such a scale. Results supported previous findings concerning the various aspects of marital interaction.

The scale consisted of twenty questions intended to measure the Verbal Accessibility of certain determinant attitudes relevant 
for marital interaction. Four response categories were provided. The scale was administered to for ty couples who were involved in marriage counseling: twenty at Family Counseling Service and twenty at the Court of Domestic Relations.

Respondents were asked to indicate to what extent they would talk about feelings and concerns important in marriage with each of four target persons--Spouse, Relative, Confidant and Counselor. Following this self rating, each respondent rated his spouse's accessibility with himself as target person. The counselors were asked to rate the respondents using the same scale. These ratings were intended to serve as validity checks, but chi-square comparisons with self ratings proved inconclusive.

The scale was constructed to measure the variable Verbal Accessibility in such a way that persons as well as items could be ranked along a continuum from least accessible to most accessible. As constructed, the twenty item scale tapped an unknown number of attitudes. Guttman Scalogram Analysis was used to determine whether we had succeeded in measuring single attitudes with at least some of the items. This procedure had the additional advantage of permitting examination of the conceptual meaning of the attitudes measured.

Scalogram analysis was attempted with the responses to the four target persons for the men and women separately at both 
agencies. With the Spouse and Counselor as target persons, no scalable areas were found in the responses of any of the four groups because of the high percentage of positive ("accessible") responses which made scalogram analys is impossible. Scalar patterns were found in the responses with the Relative and Confidant as target persons for all four groups.

Interpretations of the item content of the eight scalar patterns revealed what appeared to be a single underlying theme which is best expressed by Erving Goffman's concept of "impression management." This related to factors compelling and inhibiting communication in a given situation. This concept seemed prominent in the self avowed willingness to communicate all studied attitudes to the spouse as respondents attempted to conform to the ideal of a companionship marriage. The compelling force to be a "good client" and discuss all concerns with the Counselor seemed to be operating. Toward the Relative and Confidant, impression management reflected more discrimination in accessibility. This suggested that the respondents would communicate selectively to these target persons in order to convey a given impression.

Thus, data tended to conform to existing theories concerning marital patterns of communication. This led to the conclusion that with further refinements, an instrument useful to clinical practice could be produced. 
No measure of reliability was possible within the limits of the study. Methodological refinements are needed in the areas of item selection, separation of research from service and the control of response bias. Investigation of the effect of the personality variable could be pursued. 
A PPROVED:
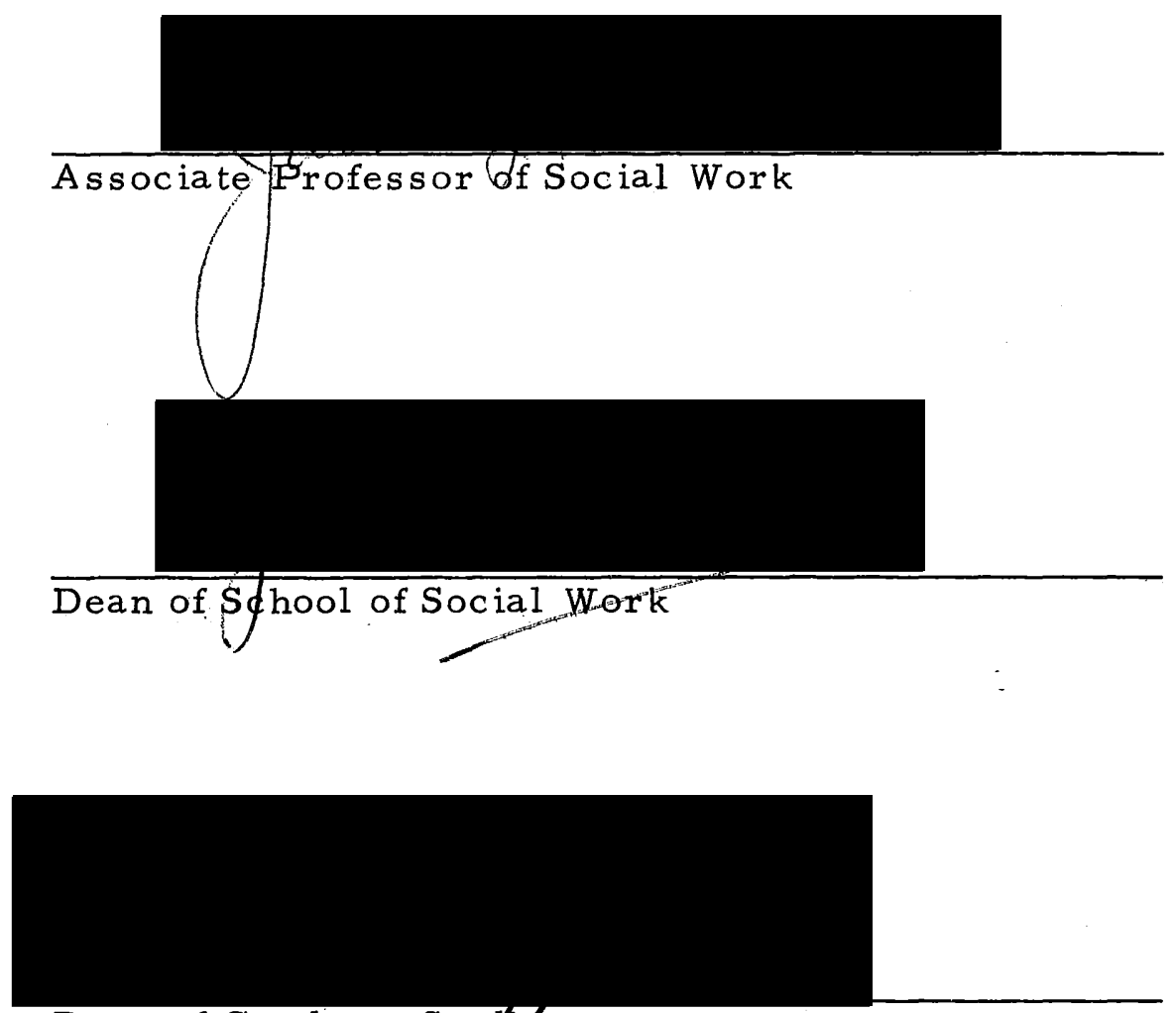

Dean of Graduate S tudibs

Date thesis is presented llay 16,1967

Typed by Illa W. Atwood for Barbara F. Kresse, et al. 


\section{A SCALE OF VERBAL ACCESSIBILITY \\ IN MARRIAGE \\ by}

BARBARA F. KRESSE

JUDITH M. DeCOURCY

NAOMI S. MANSFIELD

DOLORES M. MCLENNAN

DAVID A. WICKWIRE

\section{A THESIS}

submitted to

PORTLAND STATE COLLEGE

in partial fulfillment of

the requirements for the degree of

MASTER OF SOCIAL WORK

June 1967 
I. INTRODUCTION 1

Purpose 3

Rationale $\quad 4$

Summary 8

II. THE CONCEPT OF VERBAL ACCESSIBILITY 9

Background of Verbal Accessibility 10

Verbal Accessibility Defined $\quad 12$

Empirical Studies of VA 13

VA of the Attitude $\quad 17$

Summary $\quad 20$

III. METHOD 21

Construction of the Scale 22

Scoring $\quad 25$

Administration of the Scale $\quad 26$

The Sample $\quad 28$

Comparison of the Sample $\quad 30$

IV. RESULTS $\quad 32$

Scale Analysis Results $\quad 34$

"Relative" Scalar Patterns $\quad 37$

"Confidant" Scalar Patterns 45

Validity $\quad 55$

Response Bias $\quad 55$

V. EVALUATION AND IMPLICATIONS

Theoretical Implications 59

VA of the Attitude 62

Clinical Implications $\quad 67$

Implications for Further Research 69

$\begin{array}{ll}\text { BIBLIOGRA PHY } & 74\end{array}$

$\begin{array}{ll}\text { A PPENDIX } & 78\end{array}$ 


\section{LIS T OF TABLES}

Table

Page

I. Comparison of the Sample Population

II. Frequency of Appearance of Items in Eight Scale Patterns

III. Scale Patterns Among Items Measuring Men's Self-Avowed Freedom to Communicate Feelings to Relative

IV. Scale Patterns Among Items Measuring Women's Self-Avowed Freedom to Communicate Feelings to Relative

V. Scale Patterns Among Items Measuring Men's Self-Avowed Freedom to Communicate Feelings to Confidant

VI. Scale Patterns Among Items Measuring Women's Self-Avowed Freedom to Communicate Feelings to Confidant 


\section{A SCALE OF VERBAL ACCESSIBILITY \\ IN MARRIAGE}

\section{CHAPTER I}

\section{INTRODUC TION}

This is the second in a series of studies of marital interaction undertaken at the Portland State College School of Social Work. "Marital Interaction Theory: Some Implications for Research" (Pugh, et al., 1966), the first of these studies, reviewed the interactional approach to the study of marriage. That review concluded that the greatest challenge for research within the interactional approach to marriage is the clarification of existing concepts. The intent of the present study was to develop an instrument for clarifying one concept concerning verbal interaction in marriage.

Interaction is defined as the reciprocal exchange in which each person produces effects on the other (Sampson, 1964). Interaction permits the development of shared meanings and more accurate role-taking (performance of expected behavior). The interactional approach to marriage considers marriage to be a unity of two individuals, each occupying a position within the marriage to which a number of roles (expectations of behavior) are assigned (Hill \& Hansen, 1960). As marital roles are assigned, each partner anticipates the response of the other. To fill the role, each 
marital partner may need to change his behavior. Behavior change requires changed attitudes (tendencies to act). Information about the interaction process is obtained most directly through the precise analysis of behavior which has been observed as it occurs between persons.

Interaction provides for continuity in marriage. Beginning with Ernest Burgess (1916), the concept of the family as a unity of interacting persons has been the subject of various research s.tudies. Burgess contended that marriage and family processes cannot be defined usefully in legal terms, but should be defined in terms of the interaction of its members. Marriage exists only as long as interaction is taking place between the spouses, and, therefore, the very essence of marriage is interaction.

There are other approaches to the study of marriage: (1) the structural-functional approach (marriage as a social system); (2) the situational approach (the situation.itself, or the individual's overt behavior in response to the situation); (3) the institutional approach (marriage as a system within systems); (4) the developmental approach (the development of the family over time) (Hill \& Hansen, 1960).

Marriage as studied within the interactional framework seems particularly significant for clinical practice in social work because the focus is on continuing socialization process and personality 
development. Stryker (1959) defines socialization as the process by which the human organism acquires the ways of behaving, the values, norms and attitudes of the social units of which he is a part; and personality as the organization of persistent behavior patterns. Stryker contends that one of the advantages of the interactional approach is that it treats personal organization and disorganization as facets of the same problem. Questions regarding both can be considered within the interactional framework. Marital interaction is the focus of observation for the present research approach.

\section{Purpose}

The major purpose of the present research project was the development of a scale to measure one aspect of interaction, verbal accessibility. Polansky (1965) defines verbal accessibility as readiness to communicate verbally, and to participate in communication about, determinant attitudes. By determinant attitudes, Polansky means "those attitudes (tendencies to act) whose change seems most likely to bring about strong changes in other related attitudes" (p. 10). Appelberg (1961) clarifies this concept by stating that determinant attitudes influence the way an individual functions; they are basic, formed early in life, and are typically unconscious" (p. 10). Our scale was intended to measure the verbal accessibility of conscious derivatives of these attitudes, in and about marriage. 
If the ultimate purpose of psychological treatment intervention, including casework, is to change behavior through changing attitudes (Breedlove \& Krause, 1966), data collected showing a spouse's readiness to communicate verbally about determinant attitudes should be useful to caseworkers in dealing with marriage problems. Verbal accessibility might be used as an indirect measure of marital interaction.

\section{Rationale}

The rationale for utilizing verbal accessibility in the study of marital interaction and the analysis of the dynamics in the relationship between the marital partners is as follows:

1. Investigation of verbal communication should yield significant data for the understanding of the interaction process as it affects the personalities of the marital pair and their formation of patterns of behavior. "Communication" includes the explicit and intentional transmission of messages by which people influence each other (Ruesch \& Bateson, 1951).

Karlsson (1962) puts special emphasis on communication in marriage and regards it as basic to satisfactory adjustment. $\mathrm{He}$ found that success in marriage counseling has been achieved by improving this area. He states: 
In marriage we have at least three different problems of communication, although two of them are quite similar. One is the problem of communicating roleexpectations so that the spouses are informed about the size and direction of the adjustment they are required to make. Another is to communicate from one spouse to the other the feelings of love and tender emotions that they possibly have for each other, and a third is the problem of communicating feelings of respect and admiration (p. 37).

2. Verbal accessibility is an important aspect of verbal communication. Lack of it can inhibit the effectiveness of the marital interaction, the ability to "get close, "which Polansky (1965) believes humans are able to do best through the spoken word. The loneliness and alienation in some marriage relationships may be due to the lack of readiness of one or both spouses to discuss determinant attitudes. Karlsson (1963) found that marital satisfaction was most closely as sociated with satisfactory two-way communication.

3. Verbal accessibility is important to marriage as an ongoing socialization process. Readiness to communicate the deeper, more intimate attitudes, opinions, feelings and emotions facilitates the process by which the marital pair can acquire mutually satisfying ways of behaving.

4. Verbal accessibility is related to personality which is a major determinant in marital interaction. Interaction is a product of the personalities of the two spouses; the whole is greater than 
the sum of the parts. Rickers-Ovsiankina (1958) found that accessibility is not a rigidly fixed feature of the personality, but is influenced by age, experience, tension, central interests, environmental conditions and social situation. However, Polansky (1965) s ta tes:

We do seem to have in view a facet of personality which is relatively stable and which either determines important areas of functioning, or is closely associated with the personality dynamics which do (p. 23).

Nooney (1961) also relates verbal accessibility and personality:

VA of the deeper, more intimate attitudes, opinions, feelings and emotions, depends on personality of communicator, setting for the communication, intent of communicator in his verbalization, and his perception of the communicatee (p. 8).

5. Verbal accessibility is related to the organizational unity or disorganization of the personality of each marital partner. Polansky (1965) states: "Lack of adequate organizational unity creates impasses for the verbal expression of attitudes" (p. 42). Polansky explains that "organizational unity" of the personality, a term taken from Kurt Lewin, implies an adequate degree of differentiation, along with competent psychic apparatuses for coordinating disparate drives, etc." (p. 18).

In marriage if a spouse is unable to differentiate his feelings or affects, he would be unable to express them. If a spouse is unable to synthesize conflicting attitudes into one, he may not be 
able to verbalize them at all. Feelings may then be expressed in doing rather than talking (Eisenberg, 1962; Jaffee \& Polansky, 1962).

6. Verbal accessibility is related to one's capacity for selfobservation. Interaction between two verbally accessible spouses gets rid of anxiety and enhances the expression and development of one's self. "Self" in Pugh, et al. (1966) is defined as that which arises as an object within the personality. Self is developed in the give and take of interaction. A spouse with low verbal accessibility may have unconscious constant strong wishes to withhold close contact in defense of his self. He may fear verbalizing attitudes to his spouse, for in telling them he clearly hears himself and in so doing he may threaten his self-esteem (Polansky, 1965; Khan, 1960; Jourard, 1958). Underneath the silence may be an identity problem--a sense of inadequacy and worthlessness which threatens the marriage relationship.

7. Differences between spouses in verbal accessibility may indicate discrepancies in their development of thought. This discrepancy may have an impact on the success of their problem solving effor ts together. Vygotsky (1962) pointed out that we not only try to put our thoughts into language, we also put our language into thought. In an adult, the two have become interdependent. Vygotsky reminds us that the quality of thought determines the quality of language, but the quality of language may affect the upper limits on 
the development of thought. Using speech for rational problem solving may not occur in a marriage in which one or both of the spouses has low verbal accessibility (Polansky, 1965).

\section{$\underline{\text { Summary }}$}

In this chapter we considered why the interactional approach is important to the study of marriage. We noted that more precise analys is of marital behavior is needed in order to clarify existing concepts about the interaction process in marriage. To facilitate the analysis of one aspect of marital behavior, this project was designed to develop a scale of verbal accessibility. We stated our rationale for believing that a scale of verbal accessibility is a significant tool for clarifying existing concepts about the interaction process in marriage.

Although verbal accessibility is not necessarily an interactional variable, it may be used as a significant index of interaction affecting marital adjustment and satisfaction. Verbal accessibility is related to a marital partner's capacity for verbal communication, emotional involvement, personality change, organizational unity, self-observation and problem solving.

In the following chapter communication and the verbal accessibility concept will be considered in greater detail. 


\section{CHAPTER II}

\section{THE CONCEPT OF VERBAL ACCESSIBILITY}

Communication is intrinsic to the interactional approach to marriage when communication is defined as an interpersonal variable. For the purposes of this study communication is defined according to Ruesch and Bateson (1951) as "all those processes by.

which people influence one another." Four levels of communication are described by them as Intrapersonal, Interpersonal, Group, and Cultural. While each of these levels or networks is important, the particular level under scrutiny in this study is the Interpersonal, the one to one. This can be characterized by an exchange of receiving, transmitting and evaluating messages. As distortion in the transmission process takes place, this exchange ideally enables a direct correcting of the message. Ruesch and Bateson speak of this correction as complementation but add that "complementation is never complete... The human individual can never perceive hims elf perfectly in relation to others" (p. 280).

While the importance of non-verbal communication cannot be disputed, verbal behavior offers a vast storehouse of symbols about which there is general consensus. Unlike its non-verbal counterpart, it has the distinct advantage of being easily written and, therefore, readily available for research. Moreover, the usual 
mode of changing attitudes and behavior is through verbal means. Casework relies heavily on verbal communication to accomplish its goals as do many other modes of changing human behavior. There are few problems faced by any man which are so simple that they can be solved without the spoken or written word. Life has become so complex that symbols are mandatory for existence.

The complexities of verbal communication are analyzed by Meerloo (1952) in terms of "the many intentions that are expressed simultaneously in the word." Meerloo goes on to speak of "the known needs" underlying the function of speech and verbalizations as follows: The need to express emotions and moods; the need to make sounds; the need for contact; the need to inform, state facts; the need to formulate ideas; the need to take a position opposite the world; the need for individuation; the need to control things; the need to control others or to be controlled by them; need to express sexual desire; need for the words as a defense mechanism; the need

to express unconscious motives; the need to refuse contact (p. 84-86).

\section{Background of Verbal Accessibility}

Our concern in this study is that aspect of verbal communication which has been conceptualized as verbal accessibility. Previously verbal accessibility has been studied in the context of the casework relationship. Polansky (1965) reported that he earlier 
studied social casework relationship and found that continuance in treatment was dependent on two facets: "(a) the anticipated instrumental value of the relationship for furthering live-goals extrinsic to the relationship; (b) fulfillment of needs in the security-dependency s.pectrum within the interview itself" (p. 41). In analyzing the interview satisfaction through a series of "post-interview interviews" it was found that only one set of statements having to do with feelings about communication correlated significantly with all other dimensions of interview satisfaction. His experimental work revealed that "freedom in communication experienced by the client is a product both of his readiness and the skill with which he is met" (p. 5). Several years later Polansky began a series of research studies at Bellefaire, an institution for emotionally disturbed children in Cleveland, Ohio. The assumption was that children placed in residential treatment had either been unresponsive as out-patients or the question of their treatability outside the institution had not been raised. Therefore, the treatment task became how to open up the inaccessible child through social pressures within the institution. The components of accessibility to individual treatment were seen as attraction to the caseworker, capacity for self-observation, motivation for change, a global measure of "trust and investment in the relationship, and freedom to communicate feelings verbally in interviews" (p. 6). All of the elements were found to be interrelated 
except attraction to the caseworker. Polansky began to believe that "Freedom to Communicate Feelings" was a key dimension. He labeled this dimension verbal accessibility.

\section{Verbal Accessibility Defined}

Polansky (1965) defines verbal accessibility as "the degree of readiness of the client (or patient) to communicate verbally, and to participate in communication about, his determinant attitudes." VA is seen as a quasi-stationary equilibrium in which "readiness" for an individual depends upon his own "level" of VA as well as the release of inhibiting factors in a given situation. The meaningful unit of communication is not just the "facts" given by the client nor just the "feelings" but the set of attitudes which characterize him. Attitude is defined as a "drive or drive-derivative with an object, and with an associated affect (in short, an internalized object)" (p. 6-7). Polansky gave much consideration to the as signing of "weights" to verbalized attitudes. He cited previous attempts such as Bordin (1959) and later Truax (1963) in their separate studies of depth and Lewin!s (1935) concept of central-peripheral. This led him to seek a way of describing "asymmetrical interdependence":

That is to say, a small change in attitude $A$ leads to a large change in attitude $B$, but it takes a large change in $B$ to cause a small change in $A$... . I found that 
relationship . . . had been dealt with by Zajonc (1954)

. . . The weightier side of the interdependence he termed determinant; and the other, dependent. Hence, determinant attitudes are those whose change seems most likely to bring about strong change in other related attitudes. Clinically, we would say they result in alterations of personality structure (Polansky, 1965, p. 10).

Polansky felt that an operational definition of VA was more difficult to state. He noted that sheer verbal flow had been used by Jourard (1963) in his work on self-revelation (the process of making the self known to other persons). Polansky (1965) admitted that the more a subject is willing to discuss, the more likely he is to expose determinant attitudes. On this basis Polansky has borrowed selfavowed or self-rating techniques from Jourard and others. Polansky felt that he had obtained evidence of validity of such data, but also felt that there was considerable distortion from a variety of sources which lowered the precision of self-avowed results (p. 11).

\section{Empirical Studies of VA}

In line with the conceptualization of VA as a quasi-stationary equilibrium Polansky reasoned that it was necessary to demonstrate its stability across time; stability across varying social situations or contexts; predictability on the basis of other knowledge about the personality; fruitfulness for predicting behavior.

The first empirical studies were aimed at demons trating the 
stability of VA across time. Polansky reported that his studies with Weis s and Blum in 1961, after later correction for computational error, showed a trend toward relative stability of VA. The main evidence for temporal stability came from a study of the similar concept of social accessibility reported by Rickers-Ovsiankina and Kusmin (1958). Using a scale device they found a correlation of .52 among a group of college women retested after four years, and .69 for a group of both sexes, retested after 18 months.

The stability of VA in varying social situations as demonstrated by inter-rater reliability has been reported in several studies. Polansky in association with Blum and Weiss reported in 1961 a study at Bellefaire in which children in the institution were ranked by each of four cottage personnel to whom a child might communicate. Using Kendall's W for test of similarity of such rankings among the four, all but two W's were significant, most beyond .01. These ratings were compared with caseworker ratings of the child's VA and these were found significant at . 02 by chi square. The children's reports of their own VA were compared with these ratings. Children who rated themselves higher on VA were so rated by both caseworkers and cottage staff. These findings were confirmed during a later study by Appelberg (1961). Nooney (1960) developed a reliable method of measuring VA according to response on sentence completion. Under experimental 
conditions he found that when there was inhibition of VA, it operated uniformly, but where there was an induced increase in forces compelling communication, individual differences were such as greatly to reduce test-retest reliability.

The predictability of VA from other knowledge of the person was first.studied by an inexperienced social worker who reviewed social history summaries completed at the time of admission of children to Bellefaire. Clinical ratings of "ego strength" based on these histories were found to be significantly associated with VA at the .001 level (Polansky, 1965).

Rorschach and WISC results done at admission were reviewed with VA results for children institutionalized fifteen months. Rorschach factors concerned with overall goodness of functioning were found to be discriminating. Low IQ did not necessarily predict poor VA, but high average or superior IQ predicted high VA. Responses to aspects of Rorschach cards which generally evoke anxiety were significantly related to a high VA score. Lack of responses to anxiety arousing aspects predicted a low VA (Polansky, 1965).

The use of diagnostic groups in two child guidance clinics studied by Grace Ganter (1965) showed two factors to be most significant in predicting VA: 
(a) the child's organizational unity; and (b) the child's capacity for self-observation. Organizational unity, a term taken from Kurt Lewin, implies an adequate degree of differentiation along with competent psychic apparatuses for coordinating disparate drive, etc. (Polansky, 1965, p. 18).

Based on these studies it was inferred that a course of treatment aimed at increasing two as pects of ego-functioning, organizational unity and the capacity for self-observation, would increase VA. Such a field study was conducted by Ganter and Yeakel with the use of group treatment designed to ready the inaccessible child for individual therapy (Ganter, Yeakel, Polansky, 1965). Polansky reported that the results were encouraging.

Verbal accessibility as a predictor of treatment outcome was studied by Weber (1963). She found that children rated higher on VA three months after admission were adjudged better adapted on role-fulfillment at the time therapy was terminated. At the time of admission there was no difference in adaptation to living situation indicating that neither group was more or less "sick" than the other.

Summarizing the findings of studies of VA and closely related concepts, Polansky (1965) concluded that

VA has been found to be "flexibly stable" across time and in changing social situations; it can be predicted from history, using a crude criterion of "ego-s trength" and from psychometric data. with a similar conception in mind. It has been predicted from observations in a diagnostic group, most efficiently from those indicating over all "organizational unity" of the personality, and 
his related capacity for self-observation; and showed a striking relationship to age at admission to a children's institution. It has been observed to be negatively related to delinquency-proneness in pre-adolescent boys; and possibly to defensiveness in taking a Rorschach. Boys with identified emotional disturbance were found lower on VA: and, even among hospitalized paranoid schizophrenics a distinction on this variable could be related to depth and fixedness of pathology. VA has been found predictive of treatability in a residential setting of disturbed children and adults; it has also shown some us efulness in picking out interpersonal competence among students in two helping professions: nursing and social work. Finally, although not shown in any of the studies specifically, there is the observed negative relation of VA with familial and cultural deprivation, reported by many clinicians (p. 23-24).

Cultural differences in VA are not believed by Polansky to be clarified sufficiently to fur ther the concept. He postulated that VA would in any case be transmitted through the family of orientation. Reporting on a study by Jean Haring in an out-patient clinic for adolescents, Polansky (1965) suggested that:

. . insofar as the family of orientation may be thought to influence the VA of troubled youngsters, we are likely to find girls the more affected, and the mother as the parent who "sets the tone". . . mothers far outstrip fathers as preferred targets of communication (p. 26).

VA of the Attitude

Analogous to VA of the person is verbal accessibility of the attitude. There are two senses in which VA of an attitude was considered: (1) an individual may be more willing to discuss certain 
of his attitudes than he will others; (2.) examination of a number of individuals may reveal uniformities in regard to expressing or not expressing certain attitudes. Uniformities regarding VA of attitudes were readily apparent in studies conducted in fields closely related to VA such as Rickers-Ovsiankina (1956) in her study of social accessibility. In her population of college freshmen compared to college seniors results of items accessible correlated at .903; while seniors compared to alumni correlated at . 897 (p. 28). In the study of VA of the attitude, Polansky (1965) suggested that attitudes under test should be ones where constraints against communication are moderately high. Referring to a later Rickers Ovsiankina and Kusmin study reported in 1958, Polansky reported that "significant differences between groups occur mostly on items of generally low accessibility" (p. 29). Polansky (1965) believed this to be "an extremely difficult field to research" and recommended:

$\therefore$... that one must take cum grano salis the report by Jourard and Lasakow (1958, p.98), that some as pects of self, for instance; Tastes and Interests, Attitudes and Opinions, and Work are disclosed more than information about Personality, Money and Body (p. 29).

Polansky hypothesized that the accessibility of an attitude would vary inversely with its determinance. That is, those attitudes whose change seems more likely to bring about strong changes in other related attitudes, would be less likely to be accessible than 
less "influential" attitudes. However, studies by Appelberg (1961) at Bellefaire were either inconclusive or against the hypothesis as s.tated.

Sheer verbosity is not verbal accessibility. Cognizant of verbal flow as a defense, Polansky (1965) described the chief components of verbosity as "(a) a concentration on the current reality in a stimulus-bound fashion; (b) an over-scrupulosity about detail -. . (c) a desire to re-experience things past through retelling them . . ; (d) a desire to say something hostile while not saying it ...." (p. 31).

Polansky's (1965) conceptual theorizing has led from an immediate specific concern with the casework relationship "to the question of why people do, or do not talk at all." He limited his analysis to the enduring forces of the situation derived from the basic personality and further, "for brevity, " to account only for low VA. He proposed the following first approximation to understand the inarticulate person:

a. There may be a chronically low need to communicate verbally;

b. Constant strong wishes to withhold such contact...;

c. Fear of it; and/or

d. Deficient ability (both the latter are restraining forces which come into play only when there is a force to communicate.) (p. 33). 
$\underline{\text { Summary }}$

This chapter has summarized the concept of verbal accessibility as developed and reported by Polansky. Verbal accessibility is defined as the degree of readiness of the client to communicate verbally, and to participate in communication about, his determinant attitudes. VA is seen as dependent on two variables: (1) the release of inhibiting factors in a given situation, and (2) the enduring characteristics of the individual. The results of empirical studies done in the la.tter area have been reported. 


\section{CHAPTER III}

\section{METHOD}

Following our review of the literature in the general areas of marital interaction and verbal accessibility, we focused attention upon those studies which developed instruments for measuring verbal accessibility. None of the studies were directly concerned with marital interaction, but they did offer a considerable body of theory, method and techniques for measuring verbal accessibility. We decided that these techniques could be adapted to the specific aims of this project.

The research approaches developed by Norman Polansky and Sidney Jourard and their associates served as background for the development of our scale. Jourard and Lasakow (1958) described a questionnaire method for measuring the amount and content of self-disclosure to selected "target persons." Jourard and Richman (1963) developed a questionnaire which was designed to assess the amount of self-disclosure as a variable in its own right. Polansky, Weiss and Blum (1961) used a scale analysis technique to study verbal accessibility as a function of content and personality with children in treatment. Appelberg (1961) developed a series of scales to measure the verbal accessibility of adolescents. The Appelberg scales were designed to measure both the verbal 
accessibility of an individual and of a particular attitude. Verbal accessibility of the individual was determined by how much that individual was willing to discuss, and let others discuss with him, important feelings. Appelberg measured the verbal accessibility of the individual by counting how many items on the scale the individual was willing to discuss with a specified target person. The verbal accessibility of an attitude was measured by counting the number of individuals who were willing to discuss the attitude with the target persons. A decision was made to use this type of approach, with the necessary adjustments in content areas, target persons, and wording of the items to suit marital partners.

\section{Construction of the Scale}

To facilitate and organize the selection of items for the scale, it was decided to use content areas suggested by social roles. The idea was not to study roles as such, but to use them as a frame of reference for selecting items. Five areas of important feelings and concerns in marriage were: marital, which included the affectional and companionship roles; instrumental or work roles; attitudes toward self; parental roles; and kinship roles.

The most important criteria for the selection of items was the "determinancy" of the attitude represented by the item. Following Polansky (1965), we attempted to study the degree to which 
persons are ready to communicate important feelings. By determinant attitudes is meant those attitudes which are most "basic" to the personality functioning of the individual, and which have the most weight in influencing behavior.

Items were edited according to the informal criteria summarized by Edwards (1957). The language of the statements was kept simple to make each. item understandable to respondents who have had little formal education. That is, our intent was to develop statements which would be understood in the same way by each respondent.

To avoid statements that might be unders tood to refer to actual happenings in our respondents' lives, a stem form was designed to pose a supposition. Each statement read in the same way, i.e., "Suppose that you (had this feeling or concern), would you talk with (a specified target person) about it?" A supposition was intended to free the respondent, as much as possible, from fear of a public expression of his feelings and to relieve pressures toward conformity. The stem part of the statement was re-worded for husbands and for wives to make it understandable to them. The general content was left intact for both scales.

Four target persons were used in this test. In the instructions, respondents were asked to consider what they would discuss with each target person. The term "discuss with" was used to 
imply the reciprocal aspect of verbal communication. The principal concern was to measure verbal accessibility in marriage. In order to do this, it was necessary to demonstrate whether the accessibility of an individual to his spouse was a product of the marital relationship or representative of the individual's more general accessibility to others. Married subjects were expected to be most accessible to their spouses (Jourard, 1964).

The target persons selected were Spouse, Relative, Confidant and Counselor. Respondents were asked to name the relative and confidant with whom they would most likely discuss important feelings and concerns. The relative target was not limited to parental figures with this adult sample, to eliminate the possibility that distance or death would distort the avowed willingness to communicate in such instances. All of the respondents were involved in a counseling situation, so the choice of the counselor as a target person seemed natural and would provide for a validity check by having the counselors rate the clients as well. Another reason for using the counselor as a target person stemmed from the counselor's interest in a measure of their clients' willingness to communicate with them.

Four response categories were selected to indicate the degree of accessibility. The respondent could choose the category which best represented the extent of his willingness to communicate with a target person about eachitem. The categories were: "Yes, fully 
and completely;" "Yes, to some extent;" "No, not much;" and "No, not at all." Consideration was given to a neutral or undecided category, but this was discarded during pre-testing as respondents were able to make decisions among the other categories.

\section{Scoring}

Weights of $4,3,2$, and 1 were assigned the categories on the assumption that they represented equal intervals. The highest weight was assigned to the most positive category and the lowest to the most negative. In this way a score could be obtained for ranking between high and low accessibility. A score sheet, which is included in the Appendix, was constructed to show a total score for the individual, for the target person and for each item. However, scores were dichotomized into "low" and "high" for all of our data analysis reported in Chapter. IV.

In addition to rating thems elves on each item with each target person, respondents were asked to rate their spouses ' accessibility to them on the same items. This would serve as a validity check.

The number of items used in this scale was largely determined by a time factor. To avoid encroaching on counseling sessions, we agreed to a limit of one half hour per interview. Pre-testing showed that twenty items could be handled within this time limit. Since each item required a response for four 
target persons, the respondent was asked to make a total of eighty decisions during the main body of the test. An additional twenty responses were needed for the spouse rating. Most respondents moved through the one hundred decisions within twenty minutes without noticeable fatigue or boredom. Our impression was that respondents considered the testing a valid part of the counseling procedures to which they were already committed. There were no refusals to participate. Respondents interviewed at the Family Counseling Service were told that their scores would be made available to their counselor and could be discussed later. Data collection extended over a period of three months.

\section{Administration of the Scale}

The scale was administered to respondents in a one-to-one setting. Introduction and instructions were given verbally. Uniformity of presentation was a desired goal. Although instructions were given to the counselors on how to introduce the respondents to the project, little time was given to training or practice, and each counselor added his own style to the proceedings. A copy of the instructions is included in the Appendix.

Each item was typed on $3 \times 5$ cards of four different colors, which were placed side by side, on a rack in front of the respondent. Each color represented a different target person and was so labeled. 
Behind the card rack were four boxes which were marked with the response categories. The respondent "voted" each card by inserting it into the response box which best represented how much he would talk with a target person about that particular item. Judgments were made in regard to all four target persons before moving on to the next item. A sample question was used in the instructions to introduce the respondent to the mechanical procedures. The interviewer read aloud each item as it came up so that the respondent had the advantage of both a visual and an oral presentation. After the eighty cards were sorted, the respondent was handed a fifth stack of cards containing the same twenty items. He was asked to use the same response boxes and judge how much his (or her) spouse would be willing to discuss these items with him. For ease in scoring, each card was numbered and the same sequence of items was used with each respondent. Some effort was made to start and finish the sequence with "easy" or non-threatening items, but otherwise no ordering of the items was attempted. We assumed that the responses to the items would reflect an underlying order. Scoring was quite simple as the response box in which a card was found indicated the weight of the answer. The color of the card indicated the target person and the item identification number was typed on the card.

Additional data were collected from each respondent regarding 
age, socio-economic status, length of marriage, number of children, and so forth. These data provided for analysis of factors which might influence verbal accessibility. Each counselor rated the respondent as to how much the respondent would talk to him about the items. This score could then be compared to the respondent's self-avowed accessibility to the counselor.

\section{The Sample}

The sample population used in this study was limited to couples who were receiving counseling from either the conciliation department of the Multnomah County Court of Domestic Relations or the Family Counseling Service of Portland, Oregon. Twenty couples were interviewed from each agency. For the most part, respondents were interviewed individually in the respective agency offices. Although this method limited the number of couples which could be included in the sample within the time allotted for data collection, it was felt to be superior to a questionnaire method. By direct, individual contact, we could explain the instructions in greater detail to the respondents. We also wanted to directly observe the respondent's responses to both the procedures and the items.

We were cognizant that couples engaged in counseling were under stress. Since we were unable to compare the scale scores 
of our sample with a sample drawn at random from the general population of married couples, we have no way of knowing the effect such stress might have on the verbal accessibility of our respondents. Despite this drawback, our principal objective was to construct.a scale which could be used to measure the verbal accessibility of any married person. Comparison studies with other samples, of necessity, have been left to the future.

The study began with the Court of Domestic Relations, where the help of the couns eling staff was invaluable in constructing the instrument and in developing procedures. Family Counseling Service was called upon for cases to provide a contrast group and to increase our sample size. The Family Counseling Staff searched their case loads for interested couples and made time and space available to the research group on rather short notice for the agency.

The Court of Domestic Relations serves married couples who are approaching separation and divorce. One party in the marriage can petition the court for conciliation service and the other party is required to appear under threat of a summons. The counseling service is short-term and is oriented toward crisis intervention. The court counselors did not screen cases for the research project. They referred clients who came in at the time the research personnel were available. There were no refusals to participate, but.it is quite possible that the authority of the court influenced the 
respondents' willingness to cooperate. Quite often the counselors had not seen the couple prior to this visit. The court counselors gave their clients a brief orientation to the counseling service, stressing confidentiality, and then introduced them to the research project and research interviewer. The counselor would then inter view one client while the researcher interviewed the spouse.

Family Counseling Service proceeded somewhat differently. The participation by couples in both the counseling and the research project was entirely voluntary. On-going cases were selected with a minimum of two interviews with the counselor prior to the research interview. Clients were prepared ahead of time for the research and some made a special trip into the agency in order to participate. Three couples were interviewed in their own homes as they could not otherwise arrange time for the research interview. Family Service counselors screened their case loads individually. Several of the counselors asked for the test results which were supplied and were used in subsequent interviews with the clients. We did not offer the counselors any interpretation of the scores at that time, as we awaited the completion of the study.

\section{Comparison of the Sample}

The additional data obtained from the respondents were used to compare the samples from the two agencies. These comparisons 
are listed below in Table I. No significant differences were found between the two groups on the basis of these data. This would seem to indicate, on the basis of these descriptive variables alone, that we could pool our samples in analyzing patterns of verbal accessibility.

TABLE I

COMPARISON OF THE SAMPLE POPULA TIONS

\begin{tabular}{lccccc}
\hline \multirow{2}{*}{ Variable } & \multicolumn{2}{c}{ CDR } & \multicolumn{2}{c}{ FCS } & t \\
& Mean & SD & Mean & SD & \\
\hline Age Men & 34.05 & 3.29 & 35.25 & 2.55 & .329 \\
Age Women & 32.65 & 3.43 & 32.85 & 2.15 & .0005 \\
Education Men & 12.40 & 1.85 & 12.40 & 3.80 & 0 \\
Education Women & 12.45 & 2.10 & 12.40 & 1.75 & .0001 \\
Duration of Marriage & 10.80 & 2.34 & 10.35 & 2.05 & .11 \\
Income & 8,508 & 2.593 & 7,199 & 2.350 & .01 \\
Socio-Economic & 68.45 & 4.18 & 64.00 & 4.70 & .64 \\
Status ** & & & & & \\
\hline
\end{tabular}

* None of the t's indicate significant differences between the means for $C \bar{D} R$ and FCS.

*** Computed from U.S. Bureau of the Census (1963) scores which relate occupation, education attainment, and income. Scores can range from 0 to 99. 


\section{CHAPTER IV}

\section{RESULTS}

We planned that our scale would measure the variable "verbal accessibility" in such a way that persons as well as items could be ranked along a continuum from least accessible to most accessible. The scale as constructed contained twenty items and tapped an unknown number of attitudes. We were dependent on analys is to dis cover whether we had succeeded in measuring single attitudes with at least some of the items. We selected the Guttman Scalogram Analysis as the most feasible method of ranking persons and items at the same time. This procedure had the additional advantage of permitting us to examine the conceptual meaning of the attitudes we had tapped.

Stouffer noted that "measurements to be meaningful should be along only one dimension at a time" (Stouffer, et al., 1950, p. 46). Thus, we needed to determine the existence within our set of questions of a single meaning or dimension, that is, a "characteristic by which [the items] can be positioned in a quantitative series" (English and English, 1958, p. 153). In other words, if this unidimensional quality can be demonstrated to exist among data such as ours, then all the change in the variable would occur along a single line or continuum. Because "scalogram analysis [or scale analysis] 
provides a simple method for testing a series of qualitative items for unidimensionality" (Stouffer, et al., 1950, p. 46), we decided to use this technique as developed by Louis Guttman.

". . Scalogram analysis can perhaps be most accurately described as a procedure for evaluating sets of $\mathrm{s}$ tatements or existing scales to determine whether or not they meet the requirements of a particular kind of scale ..." (Edwards, 1957, p. 172). Green (1954) described these requirements or criteria to be satisfied as follows: "The reproducibility must be at least .90 , the item marginals must have a large range but must not include extreme values, each response category must have more non-error than error, and errors must be random" (p. 363).

Guttman "considered an area 'scalable' if responses to a set of items in that area arranged themselves in certain specified ways. In particular, it must be possible to order the items such that, ideally, persons who answer a given question favorably all have higher ranks than persons who answer the same question unfavorably" (Stouffer, et al., 1950, p. 5).

Thus, without complicated mathematics, a rank ordering of respondents anditems provides a graphic representation of the presence of a scalable area which may or may not be found to satisfy the four criteria.

In order to apply this technique easily, the response categories 
were dichotomized. Our four response categories seemed to provide the basis for a natural positive-negative dichotomy. Our final positive category included both "Yes, fully and completely" and "Yes, to some extent." Our final negative category included both "No, not much" and "No, not at all." Thus, scores with original values of 4 and 3 were converted simply to positive responses or "I," and scores with original values of 2 and 1 were converted to negative responses or "0."

\section{Scale Analysis Results}

Scalogram analysis was attempted with the responses to the four different target persons--Spouse, Relative, Confidant and Counselor. This was done for men and for women separately at the Court of Domestic Relations (CDR) and also for men and for women separately at Family. Counseling Service (FCS). Although the demographic data showed no significant differences between samples from the two agencies, there were other differences. For instance, the couples at FCS were-involved in long-term treatment for chronic marital problems; and the couples at CDR were interviewed at intake.

Of the twenty original items, two (Items 6 and 19) did not appear on any of the eight scales found. This sugges ts that the remaining 18 items were more discriminating for the sample along 
the dimension or dimensions being measured. In Table II the items which scaled one or more times are shown. Items 3 and 9 appeared on five of the eight scales; 4 and 14 on four; $1,8,15$ and 18 on three; $2,5,7,11,12,13,16$ and 20 on two; and 10 and 17 on one.

The content and number of items which were found to scale varied according to target person. None of the items scaled for men or women at either agency with the Spouse or Counselor as target persons. Of the eight scales found with the Relative and Confidant as target persons, the largest contained eight items; four had six items; and three had five items.

With the Spouse and Counselor as target persons no scalable areas were found in the responses of any of the four groups. This lack of scalability was attributed to the high percentage of positive responses which made scalogram analysis impossible.

Scalar patterns were found in the scores with the Relative and Confidant as target persons for all four groups. Although there were differences as well as similarities in the number and content of those items which scaled for each group and for each target person, in general the scales were thought to reflect a desire to preserve the impression of personal and/or marital adequacy. This protectiveness was seen in the content of the individual scales as concern for self image, concern for the spouse's image or concern for preserving the image of an adequate marital relationship. 
TABLE II

FREQUENCY OF APPEARANCE OF ITEMS

IN EIGHT SCALE PATTERNS

\begin{tabular}{|c|c|c|c|c|c|c|c|c|c|}
\hline \multirow{2}{*}{ Item } & \multicolumn{2}{|c|}{$\begin{array}{l}\text { Men } \\
\text { Relative }\end{array}$} & \multicolumn{2}{|c|}{$\begin{array}{l}\text { Women } \\
\text { Relative }\end{array}$} & \multicolumn{2}{|c|}{$\begin{array}{c}\text { Men } \\
\text { Confidant }\end{array}$} & \multicolumn{2}{|c|}{$\begin{array}{c}\text { Women } \\
\text { Confidant }\end{array}$} & \multirow{2}{*}{ Total } \\
\hline & FCS & CDR & FCS & CDR & FCS & CDR & FCS & CDR & \\
\hline 1 & $x$ & & & & $x$ & & $\mathbf{x}$ & & 3 \\
\hline 2 & & & & & & $x$ & $x$ & & 2 \\
\hline 3 & $x$ & $x$ & $x$ & $x$ & & & & $\mathbf{x}$ & 5 \\
\hline 4 & $x$ & $x$ & $x$ & $x$ & & & & & 4 \\
\hline 5 & & & & $x$ & & $x$ & & & 2 \\
\hline 6 & & & & & & & & & 0 \\
\hline 7 & & & $x$ & $x$ & & & & & 2 \\
\hline 8 & & & $x$ & & $x$ & & & $x$ & 3 \\
\hline 9 & $x$ & $x$ & $x$ & $x$ & & $x$ & & & .5 \\
\hline 10 & & & & & $x$ & & & & 1 \\
\hline 11 & & $\mathrm{x}$ & & & & $x$ & & & 2 \\
\hline 12 & $x$ & $x$ & & & & & & & 2 \\
\hline 13 & & & & & $x$ & & & $\mathbf{x}$ & 2 \\
\hline 14 & & $x$ & $x$ & $x$ & $x$ & & & & 4 \\
\hline 15 & & & $x$ & & & & $x$ & $\mathbf{x}$ & 3 \\
\hline 16 & & & $x$ & & $x$ & & & & 2 \\
\hline 17 & & & & & & & $x$ & & 1 \\
\hline 18 & $\mathbf{x}$ & & & & & & $x$ & $x$ & 3 \\
\hline 19 & & & & & & & & & 0 \\
\hline 20 & & & & & & $\mathbf{x}$ & $\mathbf{x}$ & & 2 \\
\hline
\end{tabular}


By including the maximum number of items, an increase in the number of non-scale types resulted. We could reduce the nonscale types by reducing the number of items, but we wanted as many items as possible in each scale in order to understand better the content of the dimension measured.

\section{"Relative" Scalar Patterns}

With the Relative as target person, we found six items that scaled for the men at FCS as shown in Table III. From least accessible to most accessible they were:

Item 4 - Suppose you are worried about your sexual thoughts and feelings ...

Item 3 - Suppose you feel that your wife doesn't love or respect you. . .

Item 9 - Suppose your wife isn't interested enough in the children ...

Item 1 - Suppose your wife doesn't understand the way that you feel...

Item 18 - Suppose you are worried about having a mental breakdown ...

Item 12 - Suppose you don't get along with your own parents...

These were the only items that formed an acceptable pattern.

Reproducibility was .96 . The minimum marginal reproducibility (the mean of the modal marginal frequencies) was .68 .

Eight of these men named their fathers as the Relative they would be most likely to talk with. Five chose their brothers; two 
TABLE III

SCALE PATTERNS AMONG ITEMS MEASURING MEN'S SELF-A VOWED FREEDOM TO COMMUNICATE FEELINGS TO RELA TIVE

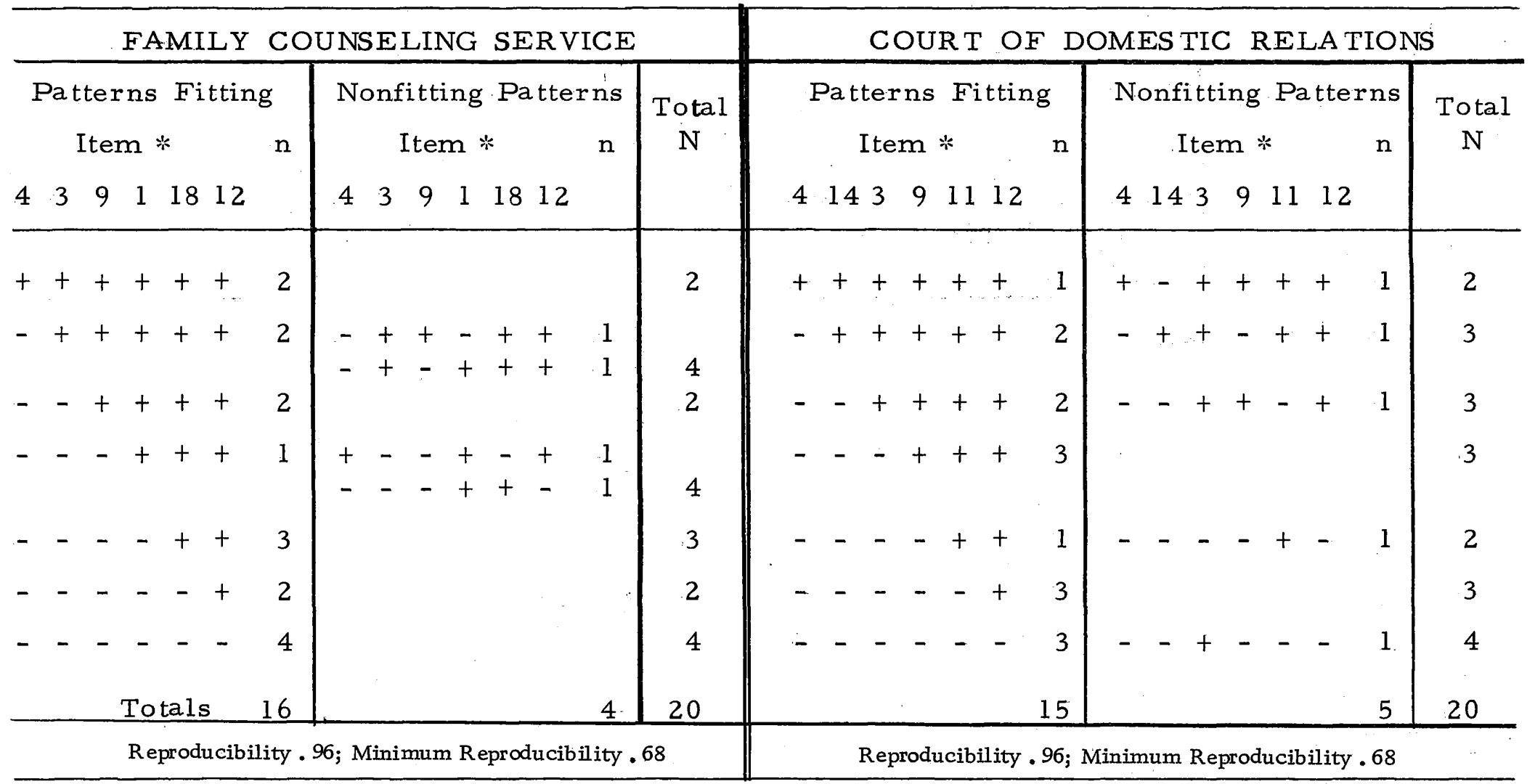

* Item 4, Own sexual thoughts and feelings; 3, Wife's love or respect; 9, Wife's interest in children; 1, Wife misunderstand way you feel; 18, Your mental breakdown; 12, Relation to own parents; 14, Marital sex relation; 2, Not good times together; 11, Job dissatisfaction. 
chose their mothers; and two chose their sisters. One man chose his mother-in-law and one chose his brother-in-law.

These men were least accessible to relatives with regard to their own sexual thoughts and feelings. They were only slightly more willing to discuss their wives' lack of love or respect and their wives' lack of interest in the children. They were somewhat more willing to discuss their wives' not understanding the way they feel and their own concern about mental breakdowns. They were most ready to discuss their poor relationship with their own parents.

Six items also scaled for men at CDR with a Relative as target person (See Table III). Reproducibility was .96, and minimal marginal reproducibility was .68 . From least accessible to most accessible these items were:

Item 4 - Suppose you are worried about your sexual thoughts and feelings ...

Item 14 -Suppose you and your wife don't have a good sexual relationship . .

Item 3 - Suppose you feel that your wife doesn't love or respect you. . .

Item 9 - Suppose your wife is n't interested enough in the children...

Item 11 - Suppose you aren't satisfied with the job you now have...

Item 12 - Suppose you don't get along with your own parents...

Five of thèse men named their mothers as the Relative they would be most likely to talk with. Three chose their fathers; two 
chose their sisters; two chose their brothers; two chose their sons; and two chose their fathers-in-law; and one his sister-in-law.

In talking with a Relative these men appeared to be least accessible with regard to their own sexual thoughts and feelings and only slightly more accessible about their marital sex relationships. They would discuss somewhat more readily their feelings that their wives don't love or respect them and their wives' lack of interest in the children. They were even more willing to discuss their job dissatisfaction and most accessible with regard to poor relationships with their own parents.

Although there were individual item differences in these two scales (FCS and CDR men), the general content of the range from least accessible to most accessible is similar. With Relatives both groups were least ready to discuss sexual and marital concerns and most ready to discuss dissatisfaction with parental relationships. It would seem that these men communicate least readily to relatives about those matters which are most intimate and personal, and most readily about those matters which are not related to marriage. Self concerns (Items 4 and 14) were least accessible; concerns about the wife's performance of expressive roles (Items 3 , 9, 1) were more accessible; and concerns which are related to factors external to the marriage (Items 11, 18, 12) were most accessible. 
Item 18, which appeared only on the scale for men at FCS, was thought to reflect their experience with long-term therapy and the fact that many of the couples in the sample from that agency had personal or family experience with mental breakdowns, thus producing a somewhat different perception of this item. In view of this, we were unable to explain with any degree of certainty why this item did not appear on the scale for women at FCS. The fact that many of the men's experiences were known to be with their wives' breakdowns is pertinent, but not conclusive.

For the women at FCS with a Relative as target person, eight items were found to scale (See Table IV.). Reproducibility was . 97, and minimum marginal reproducibility was .74 . From least accessible to most accessible, these items were:

Item 14 - Suppose you and your husband don't have a good sexual relationship...

Item 4 - Suppose you are worried about your sexual thoughts and feelings....

Item 3:- Suppose you feel that your husband doesn't love or respect you . . .

Item 15 - Suppose you are disappointed by the way your husband acts around other people...

Item 16 - Suppose you are worried that your husband spends money foolishly...

Item 9 - Suppose your husband isn't interested enough in the children ...

Item 8 - Suppose you feel that you aren't a good mother ...

Item 7 - Suppose you feel that your children had emotional problems . . 
TABLE IV

SCALE PATTERNS AMONG ITEMS MEASURING WOMEN'S SELF-AVOWED FREEDOM TO COMMUNICA TE FEELINGS TO RELA TIVE

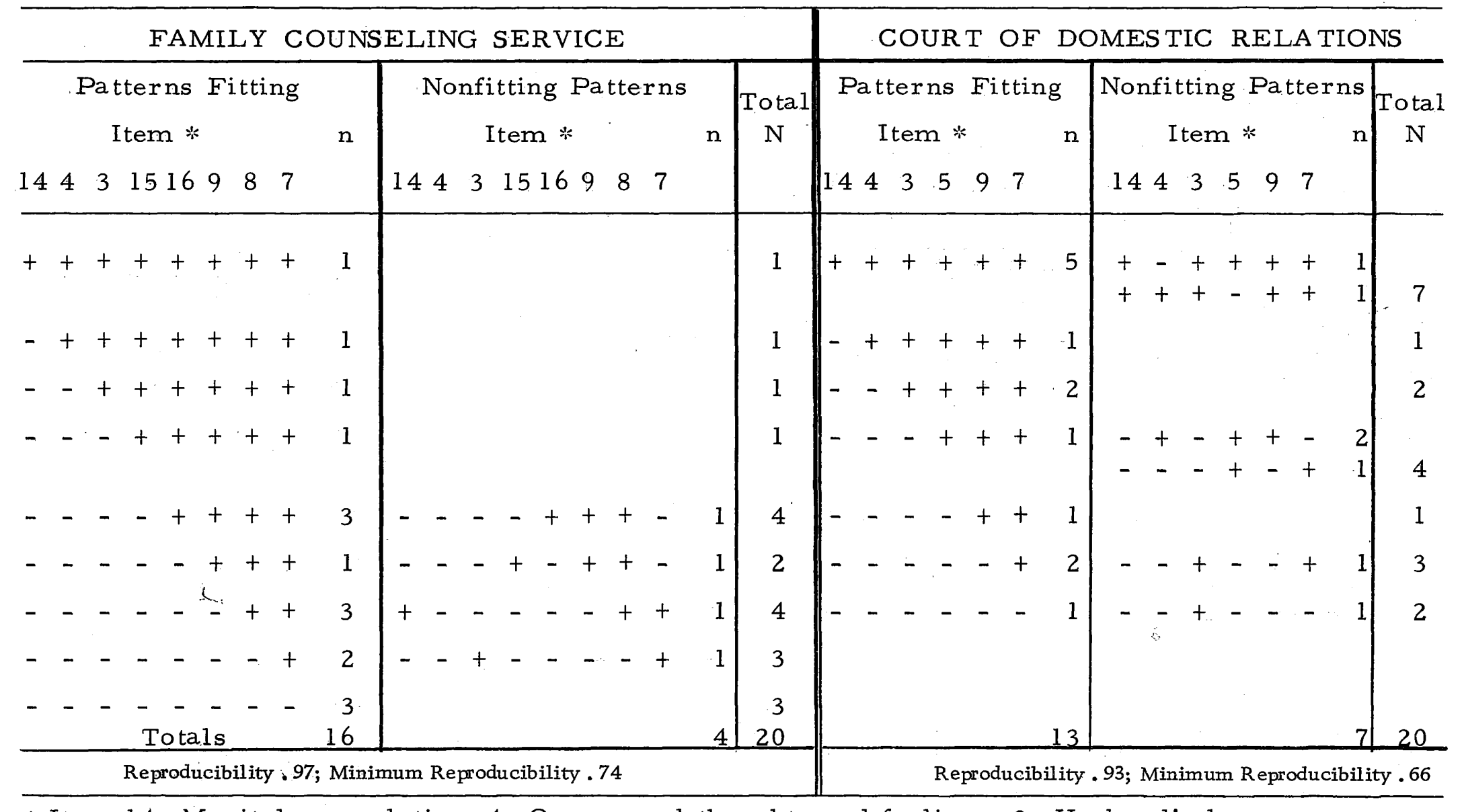

* Item 14, Marital sex relation; 4, Own sexual thoughts and feelings; 3, Husband's love or respect; 15. How husband acts around others; 16 , How husband spends money; 9 , Husband's interest in chil- $\stackrel{A}{\sim}$ dren; 8, Own feelings as parent; 7, Children's emotional problems; 5 , Own unsureness around others. 
Eight of these women named their mothers as the Relative they would be most likely to talk with. Five chose their sis ters; three chose sisters-in-law; and two chose their daughters. One chose her brother, and one chose her grandmother.

In talking to a Relative these women were least able to discuss their marital sexual relationships and their own sexual thoughts and feelings. They were more accessible to feelings about husbands' lack of love or respect, their activities around other people and their spending habits. There was greater accessibility about hus bands.' interest in the children and their own feelings about being a mother. They were most accessible about their concerns about their children's emotional problems.

Six items scaled for the women at CDR (See Table IV). Reproducibility was .93 , and minimum marginal reproducibility was

66. From least accessible to most accessible, these items were:

Item 14 - Suppose you and your husband don't have a good sexual relationship....

Item 4-Suppose you are worried about your sexual thoughts and feelings ...

Item 3 - Suppose you feel that your husband doesn't love or respect you ...

Item 5 - Suppose you feel unsure of yourself around other people...

Item 9 - Suppose your husband is n't interes ted enough in the children...

Item 7 - Suppose you feel that your children had emotional problems... 
Six of these women named their mothers as the Relative they would be most likely to talk with. Four chose their sisters; three chose aunts; two chose their daughters; and two chose their sistersin-law. One said she would talk to her brother, one to her father, and one to her cousin.

These women were least accessible with regard to their marital sexual relationships and only slightly more accessible with regard to their own sexual thoughts and feelings. They were somewhat more ready to discuss their husbands' lack of love or respect and their own unsureness around other people. They were even more willing to talk about their husbands' lack of interest in the children. They were most accessible with regard to their concerns about their children having emotional problems.

Of the eight scale patterns found, these two were the most similar in items and content especially at the extremes. Both groups of women appeared least likely to discuss with a Relative matters concerning their marital sexual relationships and their own sexual thoughts and feelings and most likely to discuss concerns involving their children. It would seem that accessibility of these women to their Relatives as indicated by these scales was related to preserving the appearance of sexual and marital adequacy, as well as to support of their own feminine roles. Intimate marital and sexual concerns (Items 14 and 4) were least accessible; 
concerns about their own as well as their husband's marital and social roles (Items 3, 5, 15, 16) were somewhat more accessible;

and matters relating to their own and their husband's concerns about the children (Items 9, 8, 7) were most accessible.

The most apparent difference between these two scales (FCS and CDR women) was the appearance of Items 15 and 16 (husbands' spending habits; husbands' behavior around other people) on the scale for women at FCS. This may be a reflection of persistent or chronic concerns about the husband's inadequacies.

\section{"Confidant" Scalar Patterns.}

A wide variety of items appeared in the scales with a Confidant as target person. This seemed to be influenced by agency differences as well as sex, personal idiosyncrasies and situational circumstances of the respondents.

We found five items that scaled for the men at FCS (See Table V). Reproducibility was . 98 , and minimum marginal reproducibility was .69. From least accessible to most accessible, these items were:

Item 16 - Suppose you are worried that your wife spends money foolishly . . .

Item 13 - Suppose your wife pays too much attention to what her family says . . or 14 Suppose you and your wife don't have a good sexual relationship... 
TABLE V

SCALE PATTERNS AMONG ITEMS MEASURING MEN'S SELF-AVOWED FREEDOM TO COMMUNICA TE FEELINGS TO CONFIDANT

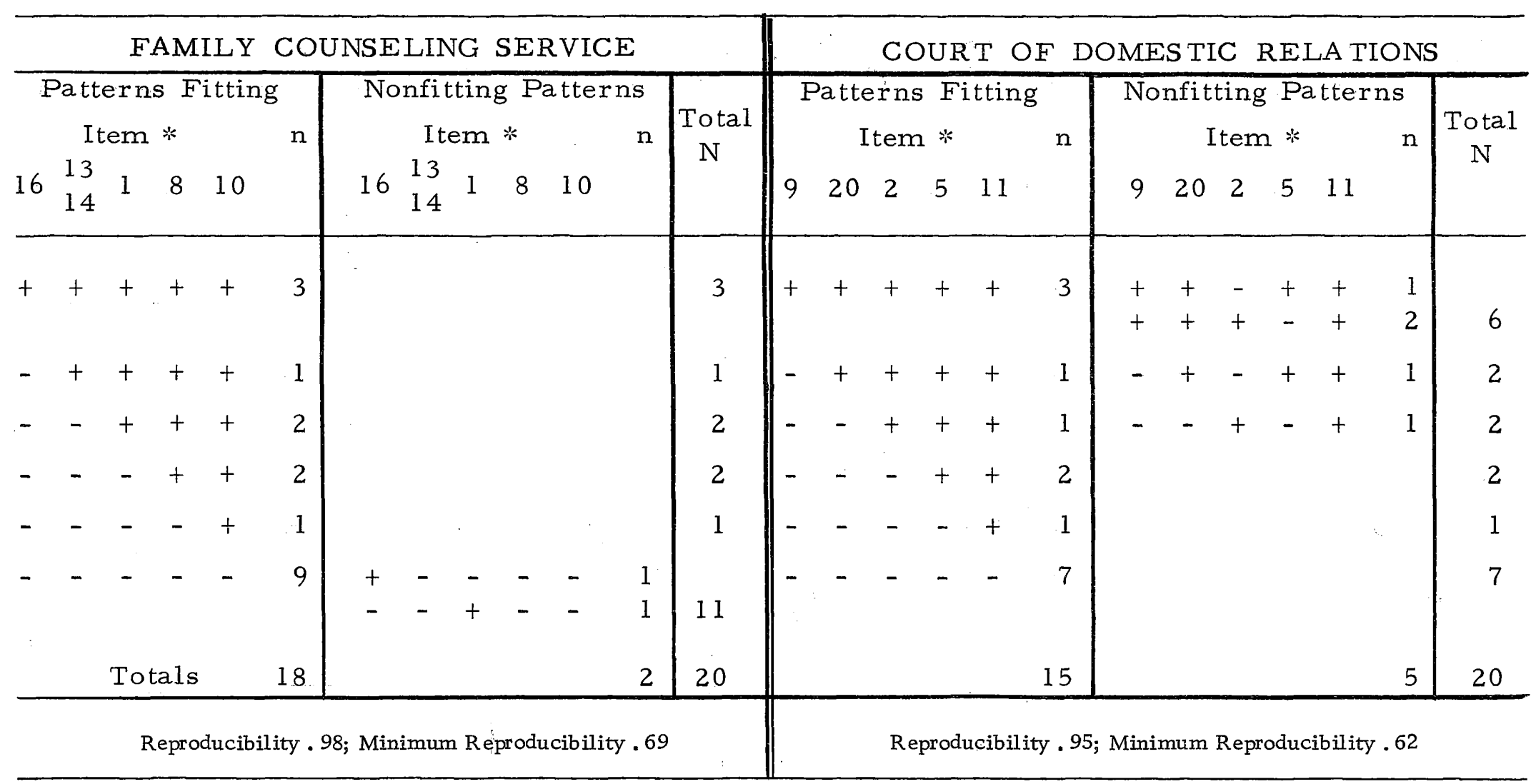

* Item 16, How wife spends money; 13, Wife's overly attentive to her family; 14, Marital sex relation; 1, Wife misunderstands way you feel; 8, Own feelings as parent; 10 , Home not pleasant; 9, Wife's interest in children; 20, Own dissatisfaction with income; 2, Not good times together; 5 , You feel unsure of self; 11 , Job dissatisfaction. 
Item 1 - Suppose your wife doesn't unders tand the way that you feel. . .

Item 8-Suppose you feel that you aren't a good fa ther...

Item 10 - Suppose you think your home isn't a pleasant place to live...

Twelve of these men named a male friend as Confidant; four named ministers and two their employers.; One said his Confidant was a female friend, and one chose his doctor.

These men were least accessible concerning their wives' spending habits. They were slightly more willing to discuss their wives' paying too much attention to their (the wives') parents or their marital sexual relationships. (These two items scaled interchangeably.) Somewhat more accessible were concerns about wives:' understanding of their feelings and that they were not good fathers. They were most accessible with regard to their homes not being pleasant places to live.

All of the items in this scale were considered internal to marriage and concerned with the adequacy of the marital relationship with emphasis on role relationships. It appeared that accessibility was related to the husband's perception of his and his wife's roles in the marriage. These men were least able to discuss with a Confidant those concerns which reflect their dissatisfaction with their wives' behavior (Items 16, 13, 14); slightly more accessible 
was concern about their wives' treatment of them as persons

(Item 1); matters relating to their own functioning in the relationship (Items 8 and 10) were most accessible.

Five items also scaled for the men at CDR (See Table V). Reproducibility was . 95, and minimum marginal reproducibility was .62. From least accessible to most accessible, these items were:

Item 9 - Suppose your wife isn't interested enough in the children ...

Item 20 - Suppose you aren't satisfied with how much money you make... .

Item 2 - Suppose you and your wife don't have a good time together...

Item 5 - Suppose you feel unsure of yourself around other people...

Item 11 - Suppose you aren't satisfied with the job you now have...

Sixteen of these men named a male friend as.Confidant, and two named their employers. One said he would talk to a female friend, and one would talk to his minis ter.

These men seemed to be least accessible with regard to their concerns about their wives' interest in the children. They were somewhat more able to talk about their dissatisfaction with their income. They were even more ready to discuss not having a good time with their wives and their own unsureness around other people. They were most accessible with regard to their job satisfaction. 
None of the more intimate, personal items appeared in this scale. All of these items related to matters other than intimate marital relationships. Thus, CDR men seemed to be most able to discuss with a Confidant those matters which did not relate to marital relations. Accessibility seemed to be related to their own masculine roles in life and to their wives only as they reflect the male role. Concern about wives' parental adequacy (Item 9) was least accessible; somewhat more accessible were areas of financial and social dissatisfaction (Items 20,2, 5); concern about their own positions in society at large (Item 11) were most accessible.

The general external nature of these items may also reflect the disengagement with spouse which these men at CDR were undergoing at the time of testing. The item relating to wife's lack of interest in the children was the only parental concern that appeared, and protection of this area might reflect the expectation that the wife would have custody of the children in the event of dissolution of the marriage.

With a Confidant as target person, six items scaled for women at FCS (See Table VI). Reproducibility was .97; minimum marginal reproducibility was .70 . From least accessible to most accessible, these items were:

Item 20 - Suppose you aren't satisfied with how much money your husband makes ... 
TABLE VI

SCALE PATTERNS AMONG ITEMS MEASURING WOMEN'S SELF-AVOWED FREEDOM TO COMMUNICA TE FEELINGS TO CONFIDANT

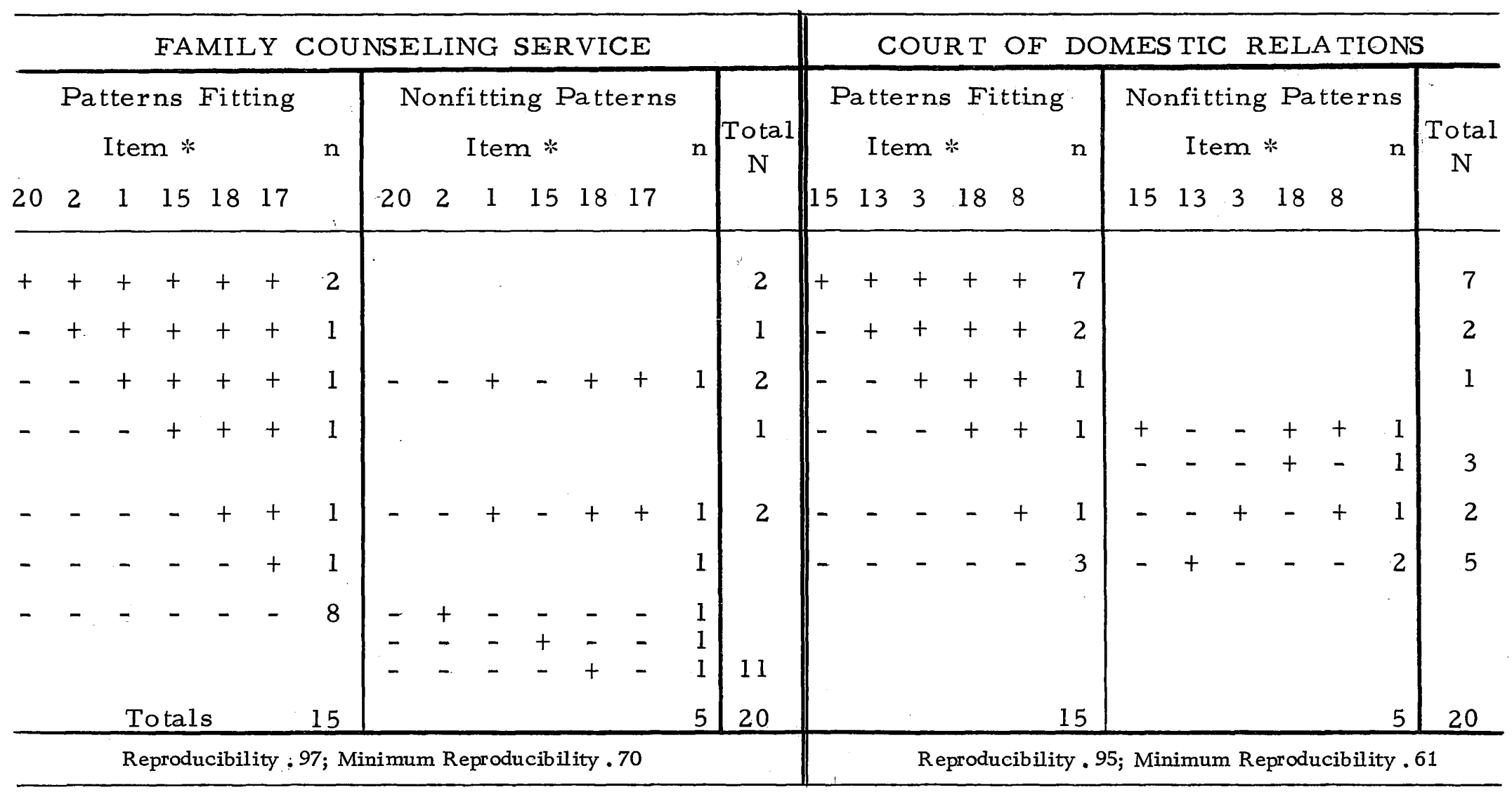

* Item 20, Own dissatisfaction with income; 2, Not good times together; 1, Husband understand way you feel; 15, How husband acts around others; 18, Your mental breakdown; 17, Husband not faithful; 13, Husband pays attention to his family; 3, Husband's love or respect; 8 , Own feelings as parent. 
Item 2 - Suppose you and your husband don't have a good time together...

Item 1 - Suppose your husband doesn't unders tand the way you feel ....

Item 15 - Suppose you are disappointed by the way your husband acts around other people...

Item 18 - Suppose you are worried about having a mental breakdown. . .

Item 17 - Suppose you are worried that your husband is not faithful to you...

Eighteen of these women named a female friend as Confidant. Two said they would talk to their doctors.

These women were least likely to discuss with a Confidant their dissatisfaction with their husbands' incomes. They were only slightly more accessible about not having a good time with their husbands, their husbands' lack of understanding and their disappointment with the way their husbands act around other people. They were more willing to discuss their own worries about having a mental breakdown. They were most accessible with regard to their worries about their husbands being unfaithful.

All of these items were related to the husband's role in the marriage. These women seemed to use their husbands' roles to protect their own images when discussing marital concerns with a Confidant. Those areas which affect their own images (Items 20 and 2) were least accessible; concerns which could more easily be blamed on the husbands' frailties (Items 1 and 15) were somewhat 
more accessible; and complaints which imply that husbands are entirely at fault and depict the wives as objects of sympathy (Items 18 and 17) were most accessible.

The appearance of Item 17 in this scale was unexpected. It is possible that infidelity for these women may have a positive connotation such as projecting blame onto the husband, or it may symbolize marriage to a "potent" male.

For the women at CDR we found five items that scaled (See Table VI). Reproducibility was . 95 ; minimum marginal reproducibility was :61. From least accessible to most accessible, these items were:

Item 15 - Suppose you are disappointed by the way your husband acts around other people. . .

Item 13 - Suppose your husband pays too much attention to what his family says ....

Item 3 -Suppose you feel that your husband doesn't love or respect you...

Item 18 - Suppose you are worried about having a mental breakdown . . .

Item 8 - Suppose you feel that you aren't a good mother. . .

Fifteen of these women said that their Confidants were female friends. Three named their ministers and two indicated their doc tors.

In talking to a Confidant, these women were least likely to discuss their disappointment about the way their husbands act 
around other people. They were only slightly more willing to talk about their husbands' paying too much attention to their families. They were more ready to discuss their husbands' lack of love or respect for them and their own worries about having a mental breakdown. They were most accessible with regard to feelings that they were not good mothers.

With one exception (Item 8) these items were also related to the husband's role in marriage. However, these women seemed to be more protective of their.husbands' roles, as opposed to using husbands' roles to protect their own images. Matters concerning husbands' social and familial weaknesses (Items 15 and 13) were least accessible; concern about husbands: treatment of them as persons (Item 3) was slightly more accessible; personal concerns about their own inabilities to fulfill role expectations (Items 18 and 8) were most accessible. Thus, this scale seemed to indicate a pattern of the wife protecting herself from recognition of concern that her husband is neither sufficiently emotionally involved in the marriage nor concerned about her reactions to him. The Confidant is utilized by these women to express anxieties about their own functioning.

The wide variety of items on the four scales with a Confidant as target person could not be conclusively explained within the limitations of this study. This variety might reflect the influence 
of situational differences and personality variables among the respondents. The Relative scales, on the other hand, were essentially similar, especially at the extremes, and the main differences were along sex lines. That is, it appeared that verbal accessibility toward a Relative was governed to a considerable extent by tradi tional kinship and cultural role expectations of males and females. Whereas, verbal accessibility toward a Confidant seemed to be dependent on the individual situations and personalities of the respondents.

This might also explain the fact that agency differences seemed to be reflected in the Confidant scales, but not in the Relative scales. The items in the Confidant scales for both the men and women at CDR seemed to be crisis-oriented sensitive areas. In addition, there were indications of the influence of the separation of the spouses, especially the lack of marital involvement seen in the men's scale. More than 50 percent of the couples in this sample had been separated from 4 to 56 weeks.

The Confidant scales for men and women at FCS indicated concerns about possibly chronic marital problems. They consisted primarily of items concerning marital roles and relationships. Only one of these couples was separated, and all had undergone long-term couns eling. 


\section{Validity}

It had been expected that validity of the scale would be indicated by comparing the Counselor's Ratings and the Spouse's Ratings with the corresponding self-avowed ratings of verbal accessibility. Chisquare comparisons were made for all twenty items and no significant differences were found. However, it was decided that these findings were inconclusive because of the small size of the sample and because of the fact that scores were to a large extent "acces sible (or positive) responses. In other words, the dearth of "inaccessible" (or negative) responses rendered these analyses ineffective.

Because of the time limitations and the general nature of the project, no attempt was made to measure reliability.

\section{Response Bias}

The high percentage of positive responses with the Spouse and Counselor as target persons suggested several conclusions. It may reflect a desire of the respondents to conform to the ideal of a companionship marriage, and feeling that they should talk about certain matters, they responded in what they perceived to be the acceptable manner. In addition, the questions may not be discriminating enough between marriage partners. They may measure verbal accessibility about marriage, but not within marriage. 
As for the Counselor as target person, it was felt that the respondents probably perceived no clear distinction between the research and counseling processes. The respondents may have expected that the results would be seen and evaluated by the counselors and, therefore, may have answered positively. This conjecture is derived from the fact that several counselors did request scores and used them in the counseling process. In addition, the introduction of the research project within the counseling process initially blurred any distinctions.

Several other factors were considered to have contributed to distortion of the scores. The phrasing of the questions as suppositions required the respondent to remove himself from the reality of his current situation. However, the respondents often expressed a marked difficulty in making a decision not based on reality. On the other hand, there were also reports from respondents that all or some of the items exactly described their current problems.

Difficulty in much the same area was reported with the Spouse Rating questions which further removed the respondent from himself and required projections. Quite often the respondents commented on the difficulty of keeping in mind that they were answering the way they thought their spouses would answer.

Concerning the items themselves, it is to be fur ther noted that in contrast to the items on previous verbal accessibility scales 
(e.g., Appelberg) many of our items either concerned undesirable situations or were phrased to make normal situations appear undesirable or objects of worry and concern. To what extent this may have influenced the outcome was difficult to determine. 


\section{CHAPTER V}

\section{EVALUATION AND IMPLICA TIONS}

The study reported here was an attempt to clarify one concept, verbal accessibility, within the interactional approach to marriage. This approach focuses on the continuing socialization process and personality development of marital partners, thus making it especially applicable to social work practice. Profes sional intervention in marital problems is directed toward changing behavior by influencing changes in problem-related attitudes. Verbal communication is the primary means by which this is accomplished. The meaningful unit of communication is not just the facts, nor the feelings, but the set of attitudes which characterize the individual.

The degree of readiness to communicate verbally, and to participate in communication about determinant attitudes was conceptualized by Polansky as verbal accessibility. Polansky (1965) used the term "determinant" to describe those attitudes which if changed have the most significant influence on behavior. He concluded that verbal accessibility is dependent on two variables:

(1) the enduring characteristics of the individual, and (2) the release of inhibiting factors in a given situation. Our goal was to develop a scale which would permit the examination of these variables by 
measuring the VA of an individual and of attitudes related to marriage. We assumed that a better understanding of forces impelling or inhibiting verbal communication would contribute in a significant way to the understanding of marital interaction.

We administered our scale to forty couples who were involved in counseling, twenty at the Court of Domestic Relations and twenty at Family Counseling Service. The difference in responses between those tested at CDR and FCS seemed to be related to the nature of the services provided by the particular agency and to the needs of the individuals who sought that service. Our analysis of demographic data collected did not reveal any significant differences between the groups of respondents from the two agencies.

The high degree of self-avowed verbal accessibility responses of both men and women to their Spouse and to the Counselor as target persons precluded scalogram analysis of these data. Scalogram analysis was possible for men and women with both the Relative and Confidant as target persons producing eight scalogram patterns.

\section{Theoretical Implications}

The high percentage of positive responses toward the Spouse as a target person may be interpreted as indicative of the nondiscriminating nature of our items. However, it is also in accordance with Jourard (1964) who found that husband and wives tended 
to disclose more to each other than to any other target person. Mayer and Zander (1966) found in their study of lower and middle class wives that a large majority of their respondents revealed their concerns more openly to their husband than to anyone else. They noted that the similarity between the two sets of wives ended at that point, however.

The positive nature of the responses to the counselor tended to validate Nooney's finding (1960) in which he reported that where there was an induced increase in forces compelling communication that individual differences were such as to greatly reduce testretest reliability. The compelling force in our testing would be the respondents' desire to present themselves in the best possible light and to please the counselor. It seemed that our respondents were not always able to discriminate between the research interviewer and their couns elor.

Our results showed no significant overall differences in VA between men and women. This is not necessarily contrary to the report of Lasakow and Jourard (1958) who found that men did not generally disclose as much about themselves as women. Our results showed a sex-linked difference in the particular items that were found to be discriminating by scalogram analysis. Komarovsky (1962) found in her studies of working class marriages that men and women reacted differently to stress within marriage, and that stress 
tended to change the communication patterns. For instance, she reported that when there is a lack of meaningful communication between marital partners, women tended to increase the level of communication to women relatives and friends. Men, however, tended to disengage themselves from the marital problems and discussed their intimate marital concerns much less than their wives. The items composing the scales for men and women from the Court of Domestic Relations seemed to follow this tendency. Also wives at CDR had a higher level of accessibility toward Relatives and Confidants than any other sample group. Their husbands were less accessible to Relatives and Confidants than other sample groups. The respondents at CDR were discussing marriages in an acute state of stress and in many instances a firm resolve to terminate the relationship was held by at least one partner. This trend toward high disclosure was not present in the FCS sample which may be a reflection of the more chronic nature of the marital problems and the mutual decision of the couples to engage themselves in a long-term counseling situation.

Our results appeared to have a single underlying theme expressed by Goffman's concept of "impression management" (1959). Impression management seems prominent in the generally selfavowed willingness to communicate all studied attitudes toward the Spouse, as respondents attempted to conform to the "ideal" of a 
companionship marriage. Toward the Counselor, the respondents attempted to present themselves as "good clients." Toward the Relative and Confidant, impression management reflected more dis crimination in concerns to be discussed. This sugges ts that respondents were selective in what they would discuss with these target people in conformance to the impression to be conveyed.

\section{VA of the Attitude}

Polansky considered VA of the attitude in two senses: (1) an individual may be more willing to discuss certain of his attitudes than he will others; (2) examination of a number of individuals may reveal uniformities in regard to expressing or not expressing certain attitudes. Scalogram analys is allowed us to examine the VA of the attitude in the latter sense. The items to be discussed reflect the attitudes of only those respondents who fit the scale types.

Of items appearing in scalar patterns, those in at least three of the eight scales will be discussed. Our focus will be on the implication of the items rather than their scale position. Appearing on five of the eight scalogram patterns were Item 3 (Suppose your Spouse doesn't love or respect you) and Item 9 (Suppose your Spouse is n't interested enough in the children). The balance of compelling and restraining forces made the attitudes represented by these items 
the most discriminating of those tested. Both items were on all Relative scalograms. In addition Item 3 appeared on the scale for women at CDR, and Item 9 on the scale for men at CDR. Both items are "other" oriented. That is, they are about the Spouse, not about the respondent. The importance of the family of orientation in trans mitting parental role patterns is well established and perhaps accounts for the appearance of Item 9. In talking with a Relative, an individual feels free to discuss this item, particularly when "blame" is cast on a Spouse. Remembering that all of the marriages studied were under either chronic or acute stress, the same sort of "blame" is represented by Item 3, with the compelling force perhaps an attempt to elicit sympathy. Also both Items 3 and 9 tend to serve as a defense against exploration of the respondent's part in the two represented problem areas.

Two items concerned with the sexual area appeared on four scalar patterns. These are Item 4 (Suppose you are concerned with your own sexual thoughts and feelings) and Item 14 (Suppose you and your Spouse don't have a good sexual relationship). Item 4 appeared on all scales with the Relative as a target person. The family of orientation serves as an outlet for the discussion of this selforiented sexual item. Only in the family of orientation are the restraining forces sufficiently weak to allow the expression of these concerns. The marital sex item was represented on three of the 
four Relative scalar patterns. The exception was that it did not appear on the Relative scale for the men at FCS. It did appear for men at FCS as discriminating toward the Confidant. This would suggest that for these men there were less restraining forces in discussing this item with a Confidant than there were in discussing it with a Relative. Thus, taboos against talking about one's own sexual thoughts were keenly felt by the men at FCS within their family of orientation.

The four items appearing on three scaling patterns are more difficult to analyze. Item 1 (Suppose you and your spouse don't have a good time together) appeared on response to the Confidant on scales for women at both FCS and CDR. It also scaled for men at FCS with the Relative as a target person. This item could be classed as revealing a marital companionship attitude, The discriminatory power toward the Confidant for both women samples reveals the use of the Confidant as a "safety valve." It was felt that this was a relatively inane item, but apparently the underlying attitude had a sufficiently strong restraining force to provide it with discriminatory power. The appearance of this item for FCS men seemed related to their concerns for their marital role, in contrast to CDR men whose scaling items generally tended to be related to instrumental role concerns.

Item 8 (Suppose you feel you aren't a good parent) scaled for 
FCS women to the Relative; for FCS men to the Confidant; and for CDR women to the Confidant. For FCS women, the family of orientation provides the situation where the balance of compelling and restraining forces makes this "self-related" parental role item scale. The family is traditionally concerned with performance of the parental role. The restraining force in this instance may well be the impression management concept discussed earlier. FCS men used their Confidant to discuss this item revealing again their concern for role performance within the marriage. CDR women could be expected to be sensitive in this area due to the situation of impending divorce and custody proceedings in which they were involved.

Item 15 (Suppose you don't like the way your husband acts around other people) appears on three scales as follows: FCS women to their Confidant; CDR women to their Confidant; FCS women to their Relative. This item has implications for the more or less public display of the manner in which the marital couples fulfill the companionship role. The appearance of this item on the Confidant scales for both women samples points to the use of the Confidant as a "safety valve." The restraining force seems to be impression management. For FCS women the Relative as a target person also seemed to be used as a "safety valve." In addition it may have indicated the use of the way the husband acts as justification 
for the chronic marital problems of the sample group.

Item 18 (Suppose you are worried about having a mental breakdown) scaled for men at FCS with the Relative and for women at both agencies with the Confidant. Men at FCS seemed to be more free to discuss mental health concerns. Both men and women at FCS were known to have more experience with mental health agencies. In a sense they were "conditioned" to discuss mental health concerns. The fact that men at FCS discussed this item with a Relative seemed reflective of the greater dependence that these men had on their families of orientation. The force compelling.CDR women to dis cuss this item with a Confidant seemed related to situational stress. The use of the Confidant as a "safety valve" is once more implied.

Items 6 and 19 were not included in any of the scalar patterns, indicating that they were not discriminating to any target person. Item 6 (Suppose you and your spouse do not agree on how to handle the children) had inherent in its make-up disagreement which would almost always necessitate verbal interaction. Likewise there appeared to be a compelling force to communicate this parental role item which had no off-setting restraining or inhibiting force, thus negating its discriminatory power. Item 19 (Suppose you are worried that you/your wife will become pregnant) failed to fit any scalar pattern. This is probably explained by the fact that a number of our couples were physically separated and others of them were incapable 
of producing children for various physical reasons.

In general items most discriminating were those least visible to those outside the marital relationship. Respondents said they were most accessible to their Spouses. This seemed linked to their expectation that this was the way their marriage was suppose to be. Their openness to the Counselor may well have been what Polansky (1965) called "the anticipated instrumental value of the relationsthip for furthering life-goals extrinsic to the relationship" (p. 41). Generally, respondents viewed the Spouse and Counselor in terms of "role to role;" interactions rather than "person to person."

The greater discrimination in matters discussed with Relatives tended to reflect the concern of the family of orientation for the respondents' parental and marital role fulfillment. The Confidant tended to be used as a "safety valve" with items revealing "complaints" about the Spouse appearing more often than other types of items.

\section{Clinical Implications}

How a husband or wife functions in his or her marital role is "invisible" to others (Mayer, 1967). Social workers have traditionally depended upon the interview to "make visible" the patterns of interaction between husband and wife. Polansky (1965) pointed out that in addition to lis tening for history, social workers should 
obtain an understanding of the attitudes which characterize the client. A scale which can accurately measure VA of the person and the attitude should facilitate this. For instance, such a scale could be utilized to examine and evalua te individual differences. Although our study did not analyze couple VA by comparing hus bands' and wives' scores, such a use of individual scores would prove valuable in diagnosing differences in marital interaction. VA scale results may well reflect the degree and quality of emotional involvement in marriage.

Comments about the scale made by the counselors and clients gave us clues to its possible uses. Counselors at the Family Counseling Service, who incorporated the scale into regular counseling sessions, found that it encouraged the clients to think about their marital communication. They stated that the scale tended to confirm problem areas that had previously been encountered and to present new areas for discussion. One counselor discussed the scale extensively with each couple, going through the ques tions and responses one by one. The clients were often surprised at each others' responses and communicated this to the counselor.

In several cases a comparatively long period of time passed (approximately four weeks) between the administration of the scale and discussion sessions with the counselor. In these cases, increase in verbal accessibility was reported by the couples. This 
indicates that administering the scale tended to affect accessibility. If further research substantiated this indication, a VA scale would contribute to both diagnosis and treatment. This would permit analysis of the dynamic relationship between personality and attitudes, and would increase understanding of marital role-taking.

\section{Implications for Further Research}

The mechanical procedures for the administration of the scale were smooth in operation and could well be used in future studies. Me thodological refinements are needed in several areas including item selection, separation of the research from agency services, and control of response bias.

Scalogram analysis of the twenty items selected indicated that we had selected some items which expressed unidimensionality for Relative and Confidant target persons. This was not true for Spouse and Counselor. The over-whelming number of positive responses to these target persons indicated the failure of the items to be discriminating.

Items were of such a general nature that marital partners could hardly avoid talking about them, unless they were completely disengaged from the marital relationship. In other words, high self-avowed VA may have, in fact, been accurate. One indication that this may have been the case was our finding that items referring 
to self-image and intimate marital concerns were indeed least accessible. Rickers-Ovsiakina and Kusmin (1958) indicate that significant differences between groups occur mostly on items of generally low accessibility. To improve our scale for the within marriage measure, items of a more intimate nature should be added. These items should tap into areas where communication is restrained by cultural conditioning, taboos, or role expectations. The scale used in this study could be expanded into a series of sub-scales more nearly approximating the approach used by Appelberg (1961). An additional number of items, perhaps twenty in each role area, could be handled in a reasonable time span if the Counselor as a target person and the spouse rating series were eliminated. The sub-scales could then be analyzed to see if they formed a scale pattern. An identified unidimensionality between the sub-scales would be the goal and would contribute to the validity of sub-scale analysis. We can speculate that role areas would form a pattern both in relation to the intimacy of the role area and the intimacy with the target person. The intimacy of the role would restrain VA, while the intimacy with the target person would be a compelling force. With improvement of the sensitivity of the scale, the Counselor as a target person could be used in future research. Future testing done within an agency should be divorced from the counseling procedures. While we appreciated the help of the 
counselors, we felt that the association with the counseling service contributed to the response bias. Respondents could not clearly distinguish between the counselor and the research interviewer. This was reinforced with the knowledge that the counselor would be informed of the test results and thus encouraged positive responses. Until the research is complete, and the instrument can be released for general usage, the results should be held in confidence. Response bias can be reduced but not entirely eliminated by such measures as insurance of anonymity and good rapport. Nye and Bayer (1962) suggest that another existing scale, such as the Lie Scale from the M.M.P.I, could be used to detect invalid answers. This would be preferable to projective tests which are cumbersome, expensive and of ten less than valid.

Instructions to the respondents were adequate for a grasp of the mechanical procedures. We were not able to clarify the concept of reciprocity in VA, nor the quality and quantity of the communication. Perserveration or nagging may have been equated with VA by respondents. We were uncertain how to proceed when the respondent indicated a readiness to discuss an item but was restrained by the target person's unwillingness to participate. Clarity might be gained by substituting the word could for would in the dis cussion question, i.e., "Suppose that you (had this feeling or concern), "would you talk with... ?" 
We were not entirely satisfied with the response categories used in this study. It was not clear that the four possible responses represented equal intervals. Dichotomizing the responses for scale analysis eliminated some of the concern, at least for the Relative and Confidant target persons. There was some indication that a different dichotomy of responses would work for the Spouse as a target person. A trial analysis was made using only the "Fully and Completely" response as positive and the rest as negative. An acceptable scalogram was obtained for the Spouse target person, but scale patterns were eliminated for Relative and Confidant. The Cornell technique for scalogram analysis, described by Goode \& Hatt (1952), might be used with better success. The Cornell method is more flexible and tailors the dichotomizations individually for each item.

The sample used in this study represented a very small, specialized segment of the universe of marital partners. Such homogeneity does contribute to control of variables. It severely limits generalizations, however. Nye and Bayer (1962) suggest Frequency Distribution Control and Ecological Matching as alternate devices for the control of variables. Increased sample size would greatly enhance data analysis potentials. In this study chi-square tests were inconclusive due to the small size of the sub-samples. A larger $\mathrm{N}$ would increase the possibility of filling cells and 
obtaining significant results. A random sample of the more general population of marital partners would allow for comparisons of several areas, i.e., marital satisfaction, stress in the marriage, s.ocial class, education, etc.

Our investigation focused on only one of the two variables Polansky associated with VA, the compelling and restraining situational forces. The other variable, the enduring characteristics of the individual, remains to be explored. This could be accomplished by combining a VA scale with personality measures. 


\section{BIBLIOGRA PHY}

1. Appelberg, Esther. Verbal accessibility of adolescents. Doctoral dissertation. Cleveland, Western Reserve Univer sity, 1961 .

2. Bordin, Edward S. Inside the therapeutic hour. In: Rubinstein's and Parloff's (eds.) Research in psychotherapy. Washington, D. C., National Publishing Co., 1959. In: Polansky's The concept of verbal accessibility. Smith College Studies in Social Work 36:1-48. . 1965..

3. Breedlove, James L. and Merton S. Krause. Evaluative research design: a social casework illustration. In: Gotts chalk's and Auerbach's (eds.) Methods of research in psychotherapy. New York, Appleton-Century-Crofts, 1966. p. $456-477$.

4. Burgess, Ernest W. The family as a unity of interacting personalities. The Family 7:3-9. 1926.

5. Edwards, Allen A. Techniques of attitude scale construction. New York, Appleton-Century-Crofts, 1957. 256 p.

6. Eisenberg, Leon. The sins of the fathers: urban decay and social pathology. American Journal of Or thopsychiatry 3:2:5-17. Jan., 1962 .

7. English, Horace B. and Ava C. English. A comprehensive dictionary of psychological and psychoanalytical terms. New York, McKay, 1958. 594 p.

8. Ganter, Grace, Margaret Yeakel and Norman A. Polansky. Intermediary group treatment of inaccessible children. American Journal of Or thopsychiatry 35:739-746, 1965.

9. Goffman, Erving. The presentation of self in everyday life. Garden City, New York, Doubleday, 1959. 259.p.

10. Goode, W. J. and P. K. Hatt. Methods in social research. New York, McGraw-Hill, 1952. 386 p.

11. Green, Bert F. Attitude measurement. In: Lindzey's (ed.) 
Handbook of social psychology. Cambridge, Addison-Wesley, 1954. p. 352-382.

12. Hill, Reuben and Donald A. Hansen. The identification of conceptual frameworks utilized in family study. Marriage and Family Living 22:299-311. 1960.

13. Jaffee, Lester D. and Norman A. Polansky. Verbal inaccessibility in young adolescents showing delinquent trends. Journal of Health and Human Behavior 3:105-111. 1962.

14. Jourard, Sidney M. The transparent self. New York, Van Nostrand, $1964.200 \mathrm{p}$.

15. Jourard, Sidney and Paul Lasakow. Some factors in selfdisclosure. Journal of Abnormal and Social Psychology 56: $91-98.1958$.

16. Jourard, Sidney M. and Patricia Richman. Factors in the self-disclosure inputs in college students. Merrill-Palmer Quarterly 9:111-148. 1963.

17. Komarovsky, Mirra. Blue-collar marriage. New York, Random House, 1964. 395 p.

18. Karlsson, Georg. Adaptability and communication in marriage. 2d ed. New Jersey, Bedminster Press, 1963. 89 p.

19. Khan, M. Masud R. Clinical aspects of the schizoid personality: affects and techniques. International Journal of Psychoanalys is 61:430-437. 1960 .

20. Lewin, Kurt. Some social-psychological differences between the United $S$ tates and Germany. Character and Personality $4: 265-293.1935$.

21. Mayer, John E. The invisibility of married life. New Society 9:272-273. 1967.

22. Mayer, John E. with Mary Zander. The disclosure of marital problems, an exploratory study of lower and middle class wives. New York, Community Service Society of New York, 1966. $145 \mathrm{p}$. 
23. Meerloo, J. A. M, Conversation and communication; a psychological inquiry into language and human relations. New York, International Universities Press, 1952. 245 p.

24. Mowrer, Ernest R. and Harriet Mowrer. The social psychology of marriage. American Sociological Review 16:27-36. 1961 .

25. Nooney, James B. Verbal accessibility as determined by perceived similarity and personality. Doctoral dissertation. Cleveland, Western Reserve University, 1960.

26. Nye, F. Ivan and Alan Bayer. Some recent trends in family research. Social Forces 41:290-301. 1963.

27. Polansky, Norman A. The concept of verbal accessibility. Smith College Studies in Social Work 36:1-48. 1965.

28. Polansky, Norman A., Erwin S. Weiss and Arthur Blum. Children's verbal accessibility as a function of content and personality. American Journal of Orthopsychiatry 3.1:153169. Jan., 1961 .

29. Pugh, Lucille S. et al. Marital interaction theory: some implications for research. Master's thesis. Portland, Oregon. Portland State College School of Social Work. 1966.

30. Rickers-Ovsiankina, Maria A. Social accessibility in three age-groups. Psychological Reports 2:283-294. 1956.

31. Rickers-Ovsiankina, Maria and Arnold A. Kusmin. Individual differences in social accessibility. Psychological Reports $4: 391-406.1958$.

32. Ruesch, Jurgen and Gregory Bateson. Communication: the social matrix of psychiatry. New York, Norton, 1951. 314 p.

33. Sampson, Edward E. (ed.). Approaches, contexts and problems of social psychology; a book of readings. New Jersey, Prentice-Hall, 1964. 576 p.

34. Stouffer, Samuel A. et al. Studies in social psychology in World War II. Vol. 4: Measurement and prediction. Princeton, Princeton University Press, 1950. 756 p. 
35. Stryker, Sheldon. Symbolic interaction as an approach to family research. Marriage and Family Living 21:111-119. 1959.

36. Truax, Charles B. and Robert R. Carkhuff. Client and therapist transparency in the psychotherapeutic encounter. Read at annual meeting of the American Psychological Association, Philadelphia, 1963. In: Polansky's The concept of verbal accessibility. Smith College Studies in Social Work 36:1-48. 1965.

37. U. S. Bureau of the Census. Methodology and scores of socioeconomic status. Working paper No. 15. Washington, D. C., 1963. $13 \mathrm{p}$.

38. Weber, Ruth. Children's verbal accessibility as a predictor of treatment outcome. Doctoral dissertation. Cleveland, Western Reserve University, 1963. 
APPENDIX 


\section{INSTRUCTIONS FOR COUNSELOR}

The following instructions are to be given to each individual included in the sample:

"In addition to our interview today, I am going to ask each of you to spend some time with $\mathrm{Mr}$./Mrs. (Researcher)

Mr./Mrs._(Researcher) will be asking you some questions to learn more about whom you talk with, about things that are of concern to you. This is a special study which will help us to be of greater help to you as well as to others. Now would you Mr./Mrs. (Client) go with Mr./Mrs.__ (Researcher) _. ."

Following your interview with the couple, please complete the attached "Counselor's Rating Sheet" for both husband and wife. The Research.Code \# blank is for our use; please ignore it. 


\section{INS TRUCTIONS TO RESPONDENTS}

We are especially interested in understanding with whom you talk about feelings or concerns that are important in marriage. I am going to ask you about a number of things that happen in families and about feelings people have. Then I will ask you with whom you would be likely to discuss each of these things or feelings. I don't want to know if these things have happened to you, but only with whom you would talk about them.

In the rack in front of you you can see four stacks of different colored cards with the same question typed on each card. Each stack is for a different person with whom you may talk. The first stack--the orange cards--is marked "WIFE" ("HUSBAND"). The white cards are for a relative with whom you would be most likely to talk. Which of your relatives would you talk with most about important feelings? (Interviewer writes name of relative on label for second stack.) The green cards are for the person outside your home and family with whom you would be most likely to talk. Who is that? (Interviewer writes name or title given by respondent on label for the third stack.) And the last stack--the yellow cards-is marked "COUNSELOR."

Now, let's look at the sample question which is on the card you see here. Suppose you feel that you should go out more, would you 
talk about this with your wife (husband)? Here are four slots where you can put the cards. They are marked Yes, fully and completely; Yes, to some extend; No, not much; and No, not at all. Now place the top orange card with the question I have just asked on it in one of these slots to show how you would discuss this with your wife (husband).

Now suppose you feel that you should go out more, would you talk with (relative) about it? Place the first white card in one of these slots to show how you would talk with your (relative) about this.

Suppose you feel that you should go out more, would you talk with (friend) about it? Place the top green card in one of the slots to show how you would talk with (friend) about this.

Suppose you feel you should go out more, would you talk with the Counselor about it? Place the top yellow card in one of these slots to show how you would talk with the Counselor about this.

That was a sample question. Now question number one is on the top card in each stack. We'll go through each stack again if you would like. (Interviewer proceeds in a similar manner through the entire list of questions if necessary. He should in all cases read each new question through once.)

Here are the same statements. Now following the same procedure, please indicate how you think your husband would talk to you about each of them. 


\section{ATTITUDE STATEMENT MASTER}

The following "sta tements" will be asked the subjects in regard to four TARGET PEOPLE: Spouse, Relative, Confidant, Counselor. The subject may respond in four different ways: Yes, fully and completely; Yes, to some extent; No, very little; and No, not at all.

\section{ATTITUDE STATEMENTS FOR MEN}

1. Suppose your wife doesn't understand the way that you feel would you talk with...

2. Suppose you and your wife don't have a good time together would you talk with.. .

3. Suppose you feel that your wife doesn't love or respect you would you talk with... .

4. Suppose you are worried about your sexual thoughts and feelings would you talk with...

5. Suppose you feel unsure of yourself around other people would you talk with. . .

6. Suppose you and your wife don't agree about how to handle the children would you talk with...

7. Suppose you feel that your children had emotional problems would you talk with . .

8. Suppose you feel that you aren't a good father would you talk with...

9. Suppose your wife isn't interested enough in the children would you talk with ... 
10. Suppose you think your home isn't a pleasant place live would you talk with...

11. Suppose you aren't satisfied with the job you now have would you talk with...

12. Suppose you don't get along with your own parents would you talk with. . .

13. Suppose your wife pays too much attention to what her family says would you talk with. . .

14. Suppose you and your wife don't have a good sexual relationship would you talk with . . .

15. Suppose you are disappointed by the way your wife acts around other people would you talk with...

16. Suppose you are worried that your wife spends money foolishly would you talk with. . .

17. Suppose you are worried that your wife is not faithful to you would you talk with . . .

18. Suppose you are worried about having a mental breakdown would you talk with ...

19. Suppose you are worried about your wife becoming pregnant would you talk with . .

20. Suppose you aren't satisfied with how much money you make would you talk with. . . 


\section{ATTITUDE STATEMENTS FOR WOMEN}

1. Suppose your husband doesn't unders tand the way you feel would you talk with......

2. Suppose you and your husband don't have a good time together would you talk with.. .

3. Suppose you feel that your husband doesn't love or respect you would you talk with. . .

4. Suppose you are worried about your sexual thoughts and feelings would you talk with . .

5. Suppose you feel unsure of yourself around other people would you talk with . .

6. Suppose you and your husband don't agree about how to handle the children would you talk with...

7. Suppose you feel that your children had emotional problems would you talk with...

8. Suppose you feel that you aren't a good mother would you talk with. . .

9. Suppose your husband is n't interested enough in the children would you talk with...

10. Suppose you think your home isn't a pleasant place to live would you talk with. . .

11. Suppose you aren't satisfied with the kind of work that your husband is doing would you talk with. . .

12. Suppose you don't get along with your own parents would you talk with.. .

13. Suppose your husband pays too much attention to what his family says would you talk with. . .

14. Suppose you and your husband don't have a good sexual relationship would you talk with. . . 
15. Suppose you are disappointed by the way your husband acts around others would you talk with...

16. Suppose you are worried that your husband spends money foolishly would you talk with. . .

17. Suppose you are worried that your husband is not faithful to you would you talk with . . .

18. Suppose you are worried about having a mental breakdown would you talk with...

19. Suppose you are worried about becoming pregnant would you talk with. . .

20. Suppose you aren't satisfied with how much money your husband makes would you talk with . . . 
Research \#

Agency

Case \#

HUSBAND

COUNSELOR RATING SHEET

The following statements will be asked the subject.in regard to four target people. The counselor will make a judgment as to how much the client would be willing to talk about each statement to the counselor: yes, fully and completely; yes, to some extend; no, very little; no, not at all.

1. Suppose his wife doesn't understand him would he talk to you

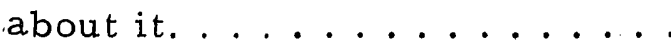

2. Suppose he and his wife don't have a good time together would he talk to you about it...

3. Suppose he feels that his wife does not love or respect him would he talk to you about it...

4. Suppose he is worried about his sexual thoughts and feelings would he talk to you about it. . .

5. Suppose he feels unsure of himself around other people would he talk to you about it ......

6. Suppose he and his wife don't agree about how to handle the children would he talk to you

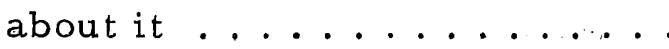

7. Suppose he feels that his children have emotional problems would he talk to you about it...

\begin{tabular}{|c|c|c|c|}
\hline Fully & Some & $\begin{array}{c}\text { Not } \\
\text { Much }\end{array}$ & $\begin{array}{c}\text { Not } \\
\text { At A11 }\end{array}$ \\
\hline & & & \\
\hline & & & \\
\hline & & & \\
\hline & & & \\
\hline & & & \\
\hline & & & \\
\hline & & & \\
\hline & & & \\
\hline & & & \\
\hline & & & \\
\hline & & & \\
\hline & & & \\
\hline & & & \\
\hline & & & \\
\hline & & & \\
\hline
\end{tabular}


8. Suppose he feels that he is n't a good father would he talk to you about it .........

9. Suppose his wife is n't interested enough in the children would he talk to you about it . .

10. Suppose he thinks his home is n't a pleasant place to live would he talk to you about it ..

11. Suppose he isn't satisfied with the job he now has would he talk to you about it........

12. Suppose he doesn't get along with his own parents would he talk to you about it.......

13. Suppose his wife pays too much attention to what her family says would he talk to you about it ..

14. Suppose he and his wife don't have a good sexual relationship would he talk to you about it..

15. Suppose he is disappointed by the way his wife acts around other people would he talk to you about it ..........

16. Suppose he is worried that his wife spends money foolishly would he talk to you about it ... .

17. Suppose he is worried that his wife is not faithful to him would he talk to you about it..

18. Suppose he is worried about having a mental breakdown would he talk to you about it . .

19. Suppose he is worried about his wife becoming pregnant would he talk to you about it . . . . . .

20. Suppose he isn't satisfied with how much money he makes would he talk to you about it.

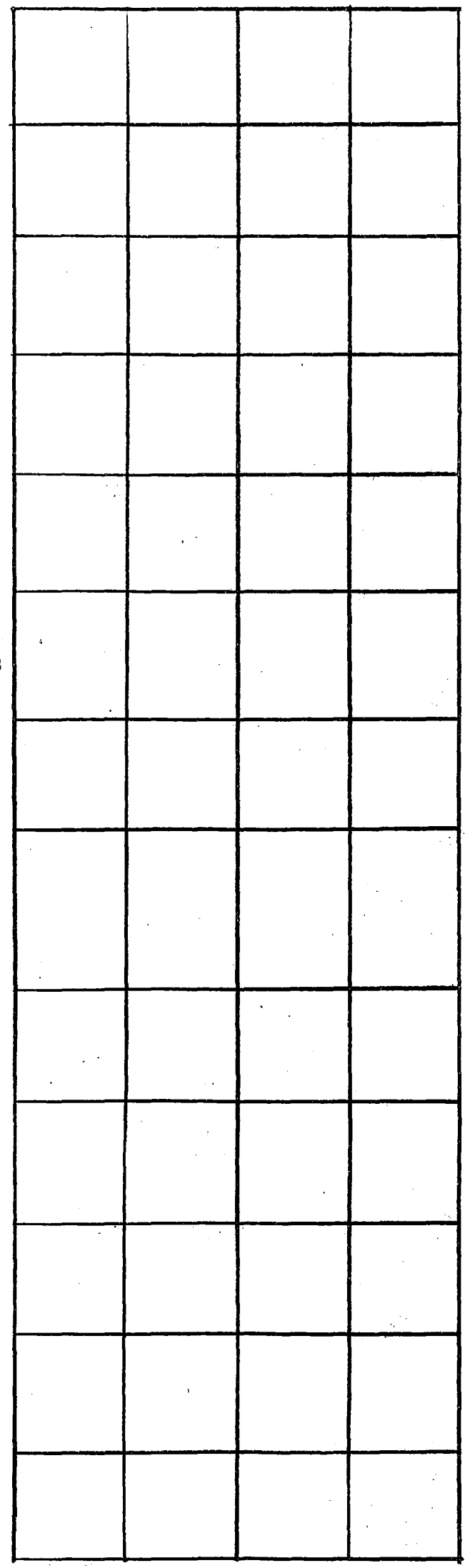


Research \#

SCORE SHEET

\begin{tabular}{|c|c|c|c|c|c|c|}
\hline $\begin{array}{l}\text { Spouse } \\
\text { Rating }\end{array}$ & Item & Spouse & $\begin{array}{l}\text { Rela- } \\
\text { tive }\end{array}$ & $\begin{array}{c}\text { Confi- } \\
\text { dant }\end{array}$ & $\begin{array}{l}\text { Coun- } \\
\text { selor }\end{array}$ & Totals \\
\hline & 1. unders tand & & & & & \\
\hline & 2. good time & & & & & \\
\hline & 3. doesn't love & & & $!$ & & \\
\hline & 4. sex feellings & & & & & \\
\hline & 5. unsure self & & & & & \\
\hline & $\begin{array}{l}\text { 6. disagree about } \\
\text { children }\end{array}$ & & & & & \\
\hline & $\begin{array}{l}\text { 7. children have } \\
\text { problem }\end{array}$ & & & & & \\
\hline & 8. not good parent & & & . & & \\
\hline & $\begin{array}{l}\text { 9. spouse uninter- } \\
\text { es ted }\end{array}$ & & ! & & & 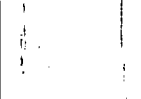 \\
\hline & 10. home not pleasant & & & & & \\
\hline & 11. dissatisfied job & & & & & \\
\hline & 12. own parents & & & & & \\
\hline & $\begin{array}{l}\text { 13. dependent on } \\
\text { family }\end{array}$ & & & & & \\
\hline & 14. sex relationship & & & & & \\
\hline & 15. spouse acts & & & & & \\
\hline & 16. money foolishly & & & & & \\
\hline & 17. unfaithful & & & & & \\
\hline & 18. mental breakdown & & & & & \\
\hline & 19. fear of pregnancy & & & & & \\
\hline & 20. dissatisfied income & & & & & \\
\hline & TOTALS & & & & & \\
\hline
\end{tabular}

Da te Interviewer \# Interviews 
Research \#

GENERAL DATA SHEET

1. Sample CDR FCS Normal... [__

2. Race .............................

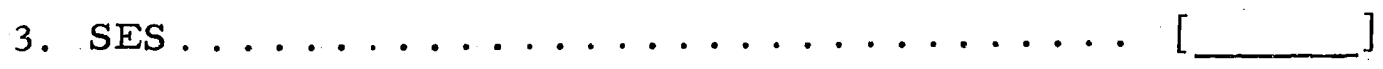

4. Age............................ [__

5. Years of school ..................... [

6. Occupation .........................

7. Income........................... [_

8. How long with present employer.......... [_ _ _ ]

9. Religion.......................... [__

10. Age of youngest child ....................

11. Number of children at home............... [

12. Number of previous marriages............. [_

13. Duration of separation - weeks..............

14. Duration of marriage - years............ [

15. Is divorce action pending..................

16. Number of interviews with counselor........ [_ _ 